\title{
The integration of long-term marginal electricity supply mixes in the ecoinvent consequential database version 3.4 and examination of modeling choices
}

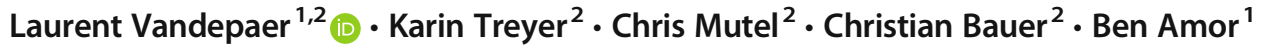

Received: 30 May 2018 / Accepted: 22 November 2018 / Published online: 11 December 2018

(C) The Author(s) 2018

\begin{abstract}
Purpose The long-term marginal electricity supply mixes of 40 countries were generated and integrated into version 3.4 of the ecoinvent consequential database. The total electricity production originating from these countries accounts for $77 \%$ of the current global electricity generation. The goal of this article is to provide an overview of the methodology used to calculate the marginal mixes and to evaluate the influence of key parameters and methodological choices on the results.

Methods The marginal mixes are based on public energy projections from national and international authorities and reflect the accumulated effect of changes in demand for electricity on the installation and operation of new-generation capacities. These newly generated marginal mixes are first examined in terms of their compositions and environmental impacts. They are then compared to several sets of alternative electricity supply mixes calculated using different methodological choices or data sources. Results and discussion Renewable energy sources (RES) as well as natural gas power plants show the highest growth rates and usually dominate the marginal mixes. Nevertheless, important variations may exist between the marginal mixes of the different countries in terms of their technological compositions and environmental impacts. The examination of the modeling choices reveals substantial variations between the marginal mixes integrated into the ecoinvent consequential database version 3.4 and marginal mixes generated using alternative modeling options. These different modeling possibilities include changes in the methodology, temporal parameters, and the underlying energy scenarios. Furthermore, in most of the impact categories, average (i.e., attributional) mixes cause higher impact scores than marginal mixes due to higher shares of RES in marginal mixes.

Conclusions Accurate and consistent data for electricity supply is integrated into a consequential database providing a strong basis for the development of consequential Life Cycle Assessments. The methodology adopted in this version of the database eliminates several shortcomings from the previous approach which led to unrealistic marginal mixes in several countries. The use of energy scenarios allows the evolution of the electricity system to be considered within the definition of the marginal mixes. The modeling choices behind the electricity marginal mix should be adjusted to the goal and scope of individual studies and their influence on the results evaluated.
\end{abstract}

Keywords CLCA $\cdot$ Ecoinvent $\cdot$ Life cycle inventory $(\mathrm{LCI})$ database $\cdot$ Long-term marginal electricity supply mix

Responsible editor: Yi Yang

Electronic supplementary material The online version of this article (https://doi.org/10.1007/s11367-018-1571-4) contains supplementary material, which is available to authorized users.

Laurent Vandepaer

laurent.vandepaer@usherbrooke.ca

1 Interdisciplinary Research Laboratory on Sustainable Engineering and Ecodesign (LIRIDE), Civil and Building Engineering Department, Sherbrooke University, 2500 boul. de l'Université, Sherbrooke, Québec J1K 2R1, Canada

2 Laboratory for Energy Systems Analysis, Paul Scherrer Institute, 5232 Villigen PSI, Switzerland

\section{Introduction}

Electricity supply is a central parameter in the life cycle assessments (LCA) of numerous products and services (Reinhard et al. 2016; Steubing et al. 2016; Astudillo et al. 2017; Gibon et al. 2017; Cox et al. 2018). In version 3.4 of the ecoinvent consequential database, electricity contributes on average $36 \%$ of the climate change impact scores of all the activities covered. ${ }^{1}$ Power generation will continue to play an

\footnotetext{
${ }^{1}$ Using the IPCC Global Warming Potentials (GWP) characterization factors with a time horizon of 100 years and the calculation approach detailed in Mutel (2018).
} 
essential role in LCA with a growing share of electricity in the final energy consumption due to trends such as the electrification of transport and heating (Bloomberg New Energy Finance 2016; World Energy Council et al. 2016; International Energy Agency 2017a). Product life cycles and supply chains are complex, spanning many countries, with sometimes very different energy landscapes (Scholten and Fynes 2017; Howell and Schwab 2018; Wiedmann and Lenzen 2018). It is therefore essential to provide LCA practitioners with accurate and consistent life cycle inventory (LCI) data for electricity supply including a broad and detailed geographical coverage. Consequential life cycle assessment (CLCA) was designed to quantify the environmental consequences of decisions and is recognized as a key method for supporting decision-making processes (Finnveden et al. 2009; Weidema et al. 2009; Menten et al. 2015; Whitefoot and Skerlos 2016; Brandão et al. 2017; Prox and Curran 2017; Salou et al. 2018). The ecoinvent center is the only organization providing a cross-sectoral consequential LCI database with a global scope (Wernet et al. 2016). Nevertheless, the approach adopted to obtain the marginal electricity supply mixes prior to the ecoinvent database version 3.4 had several drawbacks leading to inaccurate and unrealistic results. These results increased the risk of poor decisions and were an obstacle to the realization of CLCAs and the wider adoption of the methodology (Treyer and Bauer 2016).

Consequential LCI modeling aims to include the electricity supply sources that can react to a change in demand either by adjusting the operational level of the short-term marginal suppliers or through the installation of new production capacity by the long-term marginal suppliers (Astudillo et al. 2017; Brandão et al. 2017). The choice to integrate short-term marginal technologies or long-term marginal technologies in LCA models is determined by the perspective of the study. The long-term perspective was prioritized by the ecoinvent center in its version of the database using the consequential system model "Substitution, consequential, long-term" as, in most cases, long-term effects dominate the overall outcome of a decision (Ekvall and Weidema 2004; Weidema et al. 2013; Brandão et al. 2017). Long-term changes in electricity demand are better represented by mixes of technologies than by single processes since more than one marginal supplier is usually affected by demand variations (Mathiesen et al. 2009; Astudillo et al. 2017). The technology shares of the long-term marginal electricity supply mix (marginal mix in the rest of the article) indicate the magnitude at which each generation technology can adjust to a change in demand. The methodology and the choice of the data source to identify the marginal processes in CLCA remain an open debate and there is no consensus on how to identify long-term marginal electricity suppliers (Igos et al. 2015; Rajagopal 2017; Cucurachi and Suh 2017; Yang and Heijungs 2018a; Laurent et al. 2018). Several approaches have been described in the literature and three of the most commonly used methodologies are reviewed in this introduction.

The first approach was adopted in the ecoinvent consequential database version 3.01 to 3.3 (v.3.01 to 3.3) (Treyer and Bauer 2016). This approach builds upon current, average supply mixes and excludes all constrained power generation technologies to generate marginal mixes, thereby including only the technologies able to react to a change in demand. The constrained technologies are identified using historical data from national statistics, literature or expert judgments. The share of each unconstrained technology in the marginal mix is then determined by dividing its yearly production volume by the total combined yearly production from all the different unconstrained technologies. The key shortcoming of this approach stems from its reliance on historical data to identify the constraints and determine the shares, whereas CLCA evaluates future consequences of a decision requiring prospective insights (Frischknecht 2016; Pauliuk and Hertwich 2016; Yang 2016). Furthermore, the calculation of the shares of the technologies included in the mixes is based on static average yearly production values which do not give any indication of the extent to which each generation technology capacity can be expanded in response to a change in demand. This may lead to an overestimate of the role of technologies operating in the past and to an underestimate of the role of growing technologies.

A second approach relies on the use of energy system models or energy simulation tools (Dandres et al. 2017; Frischknecht 2016; Roux et al. 2017). In this approach, a base case scenario describing the future electricity production of one or several electricity markets is first defined using the energy modeling tools. Thereafter, a change in the demand for electricity is introduced into the base case creating an alternative energy scenario. Finally, the base case and the alternative scenarios are compared and the electricity generation technologies that reacted to the change in demand are considered the marginal technologies. Energy modeling tools are a good match to CLCA as they integrate economic, technical and geographical constraints, and account for the political agenda as well as the projected future power demand. In addition to the identification of marginal suppliers, they can capture a broad range of indirect effects that can be included in the consequential system boundary. Nevertheless, an important obstacle to the application of this approach is that it requires energy system modeling expertise and access to the utilized energy system model to generate and reproduce the results. Additionally, electricity markets are usually organized through national strategies and the full cause-effect chains under consideration in CLCA can span globally which requires marginal mixes to be segmented per country and data to be available worldwide (Muñoz et al. 2015). This is problematic as no prevailing energy modeling tools 
providing data globally at a sufficiently high geographical resolution currently exist. The spatial scales of energy models are either too coarse in terms geographical resolution, with global models composed of vast sub-regions aggregating several countries, or their geographical coverage is too narrow with high-resolution models specific to one or a limited set of countries. The combination of multiple energy models is possible in theory but would require vast amount of resources to gain access and to manipulate each specific model. It is, therefore, almost inevitable to that this approach is complemented by alternative methods, like the ones detailed in this introduction. In the context of an LCI database such as ecoinvent, where consistency is one of the key features, this approach is not adequate as it cannot be applied consistently across all the markets covered by the database and within a reasonable timeframe.

The third approach is based on trend analysis applied to energy scenarios (Schmidt et al. 2011; Muñoz 2015; Ghose et al. 2017; Muñoz et al. 2017; Vandepaer et al. 2018). The energy scenarios can either be self-generated via energy system models or equivalent tools or sourced from publicly available energy projections. In comparison to the second approach, it is based on the output of energy models which are often made publicly available and so the manipulation of energy models is not required. This approach compares the production of each electricity generation unit in the year the change in demand for electricity occurs to their production at a time horizon in the future when the decision ceases to have an effect. The share of each source in the marginal mix is then proportional to its respective growth rates. The third approach is selected for the identification of marginal mixes integrated into the consequential system model of the ecoinvent database version 3.4. (v.3.4). The reason for this choice is that it can be applied consistently across many electricity markets as long as projections from energy scenarios are available, and it captures prospective trends in electricity markets due to the use of these energy scenarios. Furthermore, it can be easily reproduced by practitioners to verify the results as well as to add or to modify market mixes consistently.

In this article, the methodology used to create the longterm marginal electricity supply mixes of 40 countries, as integrated into the ecoinvent consequential database v.3.4, is provided and the associated LCA results of consequential electricity markets are analyzed. Impacts of the key parameters and methodological choices on the results are evaluated. The total electricity production originating from these countries accounts for $77 \%$ of the current global electricity generation. The marginal mixes are based on public energy projections from national and international authorities and reflect the accumulated effect of changes in demand for electricity on the installation and operation of new generation capacities.

\section{Methodology}

This section is split into the following two parts: Firstly, the methodology and the data collection process used to calculate the marginal mixes are detailed. Secondly, the general approach to analyze the resulting marginal mixes and to perform the comparative analysis of alternative mixes is presented.

\subsection{Marginal electricity supply mixes: calculation and mapping the data sources}

The marginal electricity supply mixes calculated in this work are consistent with the "substitution, consequential, longterm" system model used in the consequential version of the ecoinvent database aiming to reflect long-term consequences of small-scale ${ }^{2}$ decisions (Weidema et al. 2013; Wernet et al. 2016). It is assumed that in growing markets, the sources likely to react to a change in demand are the competitive generation sources (Weidema et al. 2009). The energy pathways of the countries considered in this work either show an increase or a stabilization in the production of electricity. This power is produced to match certain forecasted demands. Hence, the resulting marginal mixes are composed of the sources with a growing production between the reference year and the time horizon (Weidema et al. 2009). Nevertheless, it should be noted that projections contradicting the scenarios used in this work and pointing towards a possible decline in demand due to, for example, alternative economic development pathways or implementation of stringent energy efficiency measures have been made in several European countries (Le réseau de transport de l'électricité 2017). If overall demand shrinks rapidly (i.e., at a rate superior to the average rate of replacement), it is possible that additional demand for electricity does not initiate the installation of new competitive units, but postpones the retirement of the least competitive units (Weidema et al. 2009). This would result in marginal mixes composed of obsolete generation units with significantly different environmental impacts.

The marginal electricity supply mixes were calculated using Eq. (1) from (Schmidt et al. 2011; Muñoz 2015).

$S_{i, T}=100 \cdot \frac{P_{i, T}-P_{i, r}}{\sum_{i}^{n}\left(P_{i, T}-P_{i, r}\right)}$

Where:

$i \quad$ electricity-producing technology

$T$ the year chosen as the time horizon

$r$ the year chosen as a reference for the time of the decision

\footnotetext{
${ }^{2}$ Small-scale decisions correspond to choices that do not influence the key parameters defining a market such as volumes, constraints and production costs and can be assumed to be linearly related to the size of the change (Weidema et al. 2013)
} 
$P \quad$ the quantity of electricity generated at time $T$ or $r$ by technology i

$n \quad$ includes all unconstrained electricity producing technologies with a growing production at $T$ with respect to $r$

$S$ the share that supplier $i$ contributes to the marginal mix given a time horizon $T$

Equation (1) is fed by data from energy projections and compares the production of electricity from the electricity generation technologies available in a specific market between a reference year and a year chosen as the future time horizon. The reference year corresponds to the year at which the decision causing a change in electricity demand is taken. In this work, the year 2015 is used as the reference year as it is the last year in which actual data on electricity production was reported in the different energy outlooks or in energy statistics. The time horizon corresponds to the year when the installation of new capacity caused by a change in electricity demand is expected to become operational. The year 2030 is selected as it provides a reasonable time interval to allow these changes to occur and also for data availability reasons not allowing to choose a shorter and still relevant time-frame (Weidema 2004; Consequential-lca 2015a).

\subsubsection{Geographical coverage and sources of the energy scenarios}

Public energy projections realized by national or supranational authorities are used as a source of data to calculate the marginal mixes. Public projections generally provide one reference scenario that follows a business-as-usual market trend and account only for energy and climate policies enforced at the time of the modeling. In cases where several pathways are available in the outlooks, scenarios which are consistent with this narrative are selected as base case corresponding to the implementation in the ecoinvent database. The marginal mixes are modeled on the level of political country boundaries as energy policy is generally determined at the national level (Muñoz et al. 2015). Energy scenarios were collected for the following countries: Australia, Brazil, Canada, Chile, China, India, Japan, Norway, South Africa, Switzerland, Russia, the USA, and the 28 European Union member countries (EU-28). In addition to Switzerland, these countries were selected based on their presence in the EU-28 or the importance of their share in the global electricity production. A short description of the different energy scenarios is provided in Table 1.

As the ecoinvent database requires global coverage of product-specific markets, a marginal mix for the Rest of the World (RoW) is used for the remaining countries. The marginal mix for the RoW market is calculated by subtracting the global projections from the "current policies" scenario from
Table 1 Description of the energy scenarios used to quantify marginal electricity supply

EU-28: scenarios from the European Union Reference Scenario 2016 published by the European Commission are used to calculate the marginal electricity supply mixes (European Commission 2016). The Reference Scenario assumes the continuation of current market trends and the compliance of Member states to energy and climate policies enacted in the EU at the end of 2014.

China, India, South-Africa, Japan, Brazil, Russia: the World Energy Outlook from the year 2016 (WEO 2016) published by the International Energy Agency serves as a source for data (International Energy Agency 2016). Projections in this document are realized using the World Energy Model (International Energy Agency (IEA) 2016). The "current policies" scenarios are used to create marginal supply mixes. This set of scenarios considers policies that are in place until mid-2016 and business-as-usual economic trends.

Australia: projections from the electricity network transformation roadmap 2016 (Graham 2015) are used to generate the marginal electricity supply mixes. This report is a joint publication prepared by the Commonwealth Scientific and Industrial Research Organization (i.e., the federal government agency for scientific research in Australia) and the Energy Networks Association from Australia. The four pathways provided are ambitious and none of the scenarios corresponds to a development of the energy system that follows the business-as-usual (BAU) trend. The "set and forget" scenario is used to build the electricity supply marginal mix for Australia as it is the most conventional among the four pathways. No other comparable energy scenarios for Australia could be identified to verify whether this scenario is in the range of a BAU scenario. Further data collection should be performed in cases where electricity from Australia plays an important role in the LCA scores.

Canada: the reference pathway from the report Canada's Energy Future 2016 published by the National Energy Board is used to build the electricity supply marginal mix (National Energy Board of Canada 2016). This report considers climate and energy policies in place in 2016 and current trends for the price of oil and gas.

Norway: projections realized jointly by the IEA and the "Nordic Energy Research and Nordic Council of Ministers" are used to calculate the electricity supply marginal mixes (Nordic Energy Research and International Energy Agency 2016). The reference scenario of this report is the "Carbon-Neutral Scenario" and is used to calculate the marginal supply mixes. It is the only scenario from the report for which market compositions are shared. This scenario implies the implementation of new policies in other energy sectors and is not fully consistent with the storylines used in the other energy outlooks. The projections were compared to other energy scenarios about Norway from less recent sources where comparable conclusions are reached (Rosenberg et al. 2015). For example, this report confirms that no thermal power sources join the electricity mix in 2030 which is the time horizon used to calculate the marginal mixes.

Switzerland: the study "Swiss Energy Perspectives for Switzerland until 2050" (i.e., Die Energieperspektiven für die Schweiz bis 2050) is used as a source of energy scenarios (Prognos 2012). This document was commissioned by the Swiss Federal Office of Energy in 2012 and details national energy strategies for Switzerland. Among the different pathways provided by this document, the scenario Political Measures $\mathrm{C} \& \mathrm{E}$ variant (i.e., Politische Massnahlmen variante $C \& E$ ) is used to determine the marginal electricity supply mix. This scenario is the closest to the current policies' scenario given the latest development of the Swiss energy regulatory framework. Indeed, in May 2017, Swiss voters accepted the revision of the law on energy approved by the Swiss parliament in 2016 which aims to reduce energy consumption, improve energy efficiency, promote renewable energies and gradually 
Table 1 (continued)

phase-out nuclear power (Confédération Suisse 2016).

USA: the reference case projection published in Annual Energy Outlook 2017 from the US Energy Information Administration is used to create the marginal electricity supply mix (US Energy Information Administration 2017). This outlook is characterized by the continuation of current energy regulations and economic trends.

Chile: the scenario "Escenario C" from energy projections published by the Chilean Ministry of Energy (Ministerio de Energía 2017) are used to calculate the marginal mix for Chile. This scenario follows the reference trend in terms of demand, technology development, the price of renewable energy and externality cost.

the World Energy Outlook 2016 (WEO) of the International Energy Agency (2016) and the sum of the country-specific scenarios collected during this work. The country-specific projections are summed together per technology and per year (e.g., wind onshore in 2020 figures were added together for all countries for which scenarios were identified). These sums are then subtracted from the WEO 2016 global projections. This theoretically provides one aggregated projection for the countries where scenarios were not available while excluding the country-specific projections. However, due to inconsistencies between country-specific scenario and the WEO 2016, the world projections for few electricity generation technologies are sometimes less than the sum of the projections per country for the same technology (e.g., global wind onshore projection in 2020 might be less than the sum of wind onshore countryspecific projections). This results in negative projection numbers for specific technologies in the RoW region, which are set to zero in the RoW marginal mix.

The data of the different energy pathways is fed into Eq. (1) to calculate a preliminary version of the marginal mixes. At this stage, the marginal mixes still follow the technological and geographical resolution used in the energy scenarios. The next two sub-sections describe how the resolution of the energy scenarios is matched to the resolution used in the ecoinvent database from a technological and geographical point of view.

\subsubsection{Technology "mapping" with ecoinvent}

The approach to link electricity generation processes from the energy scenarios to corresponding LCI datasets in the ecoinvent database is detailed in this section. Transport and distribution losses are modeled in a similar fashion to the approach used in the attributional versions of the database, as detailed in Treyer and Bauer (2016).

Electricity generation technologies are generally detailed at a lower technological resolution in public energy scenarios (i.e., more aggregated) than in the ecoinvent database (Vandepaer and Gibon 2018). For this reason, the technological classification from the energy scenarios must be disaggregated to correspond to the level of detail used in the ecoinvent database. In this work, the disaggregation is realized for wind power, hydropower, and coal-fired sources.

For wind power, the distinction between offshore and onshore wind exists in the ecoinvent database, but not in the energy pathways. A disaggregation between both types could only be performed for the EU-28 Member States due to the lack of information for the other locations and the time resources allocated to this project. In the EU-28 countries, projections from Wind Europe (2015) describing the anticipated electricity production until 2030 for onshore and offshore wind sources are used to differentiate the electricity production labeled as wind in the energy scenarios. Once disaggregated, the LCI dataset "Wind, $>3 \mathrm{MW}$ turbine, onshore" is used to represent onshore wind and "Wind, 1-3MW turbine, offshore" for off-shore wind. In the non-EU-28 countries, wind power categories are matched to the onshore wind power dataset.

In the case of hydroelectricity, this source is mostly aggregated under a single technology label in the energy outlooks. In contrast, four different hydro technologies datasets exist in the ecoinvent database, namely reservoir alpine region, reservoir non-alpine region, reservoir non-alpine region tropical and run-of-river. In this case, data from Itten et al. (2012), providing the split between the reservoir and run-of-river plants for specific regions and countries, and from Treyer and Bauer (2016) are used to disaggregate the electricity production from hydropower.

Regarding coal power, this technology is grouped under a single label in the energy scenarios whereas there is a distinction between hard coal and lignite in the ecoinvent database. For this technology, data from the International Energy Agency (2017b) providing the distribution of hard coal and lignite plants are used to differentiate the fuels.

In other cases where there is not sufficient data available to substantiate any disaggregation or in the cases where technologies in the energy scenarios and the ecoinvent database are detailed at a comparable resolution, one technology from an energy scenario is matched to one technology in the ecoinvent database (one-to-one matching). Solar categories in the energy outlooks are matched to slanted-roof installation, multicrystalline silicon solar photovoltaic (PV) datasets. Solar PV datasets are also used as a proxy for concentrated solar power (CSP) as this technology is not modeled in the ecoinvent database. ${ }^{3}$ The technologies labeled as bioenergy in the scenarios are matched to the wood combustion electricity generation dataset "electricity production, wood, future." This dataset was created for specific use in the consequential database and consists of an adaptation of the production process for heat and electricity with wood chips in a state-of-the-art (as of 2014) co-generation plant with a capacity of $6667 \mathrm{~kW}$. The efficiency, relevant exchanges, and outputs of the original co-

\footnotetext{
${ }^{3}$ The integration of a CSP dataset will be part of the release of ecoinvent version 3.5 and the marginal electricity markets will be adapted accordingly.
} 
generation dataset were adapted to create a power-only bioenergy unit. ${ }^{4}$ The reason for the creation of this substitute is that there was no widely adopted bioenergy technology dataset in the ecoinvent database with electricity as determining product. As explained further in this section, electricity as a dependent by-product of a multi-output process means that the electricity generator is considered a constrained technology and cannot supply the marginal mix.

Nuclear power categories from the energy pathways are represented by second-generation nuclear pressure water reactor datasets available in the ecoinvent database. Finally, technologies that have not reached a commercial scale ${ }^{5}$ are matched to the technologies considered to be the closest equivalent available in the ecoinvent database. Mapping tables specific to each energy scenario, showing which LCI dataset or group of datasets corresponds to which generation technologies from the energy scenario, are available in the first section of the Electronic Supplementary Material (ESM 1).

\subsubsection{Geographical "mapping" with ecoinvent}

The spatial scale of the ecoinvent database and the energy pathways are different. In the ecoinvent database, the geographical subdivisions of the various markets of products (e.g., electricity markets) must be equivalent across the different system models supported by the database. The attributional versions of the database provide the highest geographical resolution with a total of 169 region- or country-specific electricity markets and thus determines the resolution of the consequential database. Based on the limited availability of projections for national future electricity supply, energy scenarios were collected for 40 countries and serve as a source of data for the definition of the marginal electricity market mixes of the 169 regions or countries considered on each version of the ecoinvent database. The geographical coverage is presented in Fig. 1.

The mapping of the electricity scenarios to the ecoinvent electricity markets is performed in three different ways. First, in 36 of these 40 countries, one country corresponds to one market in the ecoinvent database and no disaggregation is

\footnotetext{
${ }^{4}$ According to Gibon et al. (2017), biopower technologies can generate life cycle climate change impacts ranging from 28 to $194 \mathrm{~kg} \mathrm{CO} 2$ eq./MWh. This compares to an impact score of $37 \mathrm{~kg} \mathrm{CO} 2 \mathrm{eq} / \mathrm{MWh}$ for the created power only bio-energy unit. This lower score can be justified using state-of-art technology for the original dataset and the fact that the work of Gibon and colleagues contains other fuels than wood leading to higher emissions. The share of bio-energy in the largest electricity markets is minor: $0 \%$ in China, $0 \%$ in the USA, $0 \%$ in India, 3.4\% in Russia, $4.3 \%$ in Japan, $4.2 \%$ in Canada, and $0 \%$ in Germany. Therefore, the use of this substitute was considered as acceptable until a more adequate dataset becomes available.

${ }^{5}$ These technologies play a minor role in the marginal mixes integrated into the database. Indeed, there is only one occurrence in the case of Australia with direct injection carbon engines (3\%) which is matched to the hard coal dataset. Other cases which occurred in the sensitivity analysis and the matchings are detailed in the ESM.
}

required. Second, in country-regions such as China, India, Canada, and the USA, one national energy scenario per country was collected and one marginal mix was calculated based on them. Nevertheless, these countries are divided into subregions (e.g., provinces in Canada, States in the USA) in the ecoinvent database. In these cases, the single marginal mix calculated per country is applied to its different sub-regional markets (i.e., technology shares are equal in each sub-region). Third, in the remaining countries where no specific marginal mixes were calculated, the marginal market compositions for the RoW are applied.

Finally, the location of the generation technologies comprising the marginal mixes is determined. The location of the technologies is equal to the market location when datasets at the market level are available. ${ }^{6}$ In cases where no datasets at the market level are available, global datasets are used.

\subsubsection{Comparison of methodologies used in consequential system models of different ecoinvent versions for specification of electricity markets}

The approach used in the consequential system model of ecoinvent version 3.01 to 3.3 to determine the marginal electricity mixes was based on several stages. The first step consisted of identifying and excluding the generation sources considered as constrained such as imports, cogeneration units or electricity generation from peat and oil power plants (see Table 2: Treyer and Bauer 2016). The identification of the marginal technologies was then determined by data processing rules implemented in the ecoinvent linking algorithm (Weidema et al. 2013). These rules specified that the marginal electricity supply mixes should only include technologies classified as "new" or "modern" when these were available. In cases where they were not available, activities with a "current" technology level could supply the marginal mixes. Nevertheless, processes with "new" or "modern" technology levels were not systematically modeled in the ecoinvent database. In the case of electricity processes, "current" technologies identified earlier as unconstrained were reclassified as "modern" without further changes. Thus, in practice, activities corresponding to "current" technology level usually supplied the marginal markets. Once the marginal technologies were identified, their shares in the marginal mix were determined by their current annual production volumes.

In the consequential system model of ecoinvent v.3.4, the linking algorithm is replaced by a so-called "market override": electricity markets are determined by the procedure described in the previous section and manually

\footnotetext{
${ }^{6}$ In China and India, markets are divided into sub-regions and generation technologies are further differentiated at the provincial level which is one level below. The provincial distribution of production volumes of each technology in the marginal mix is proportional to current production numbers.
} 


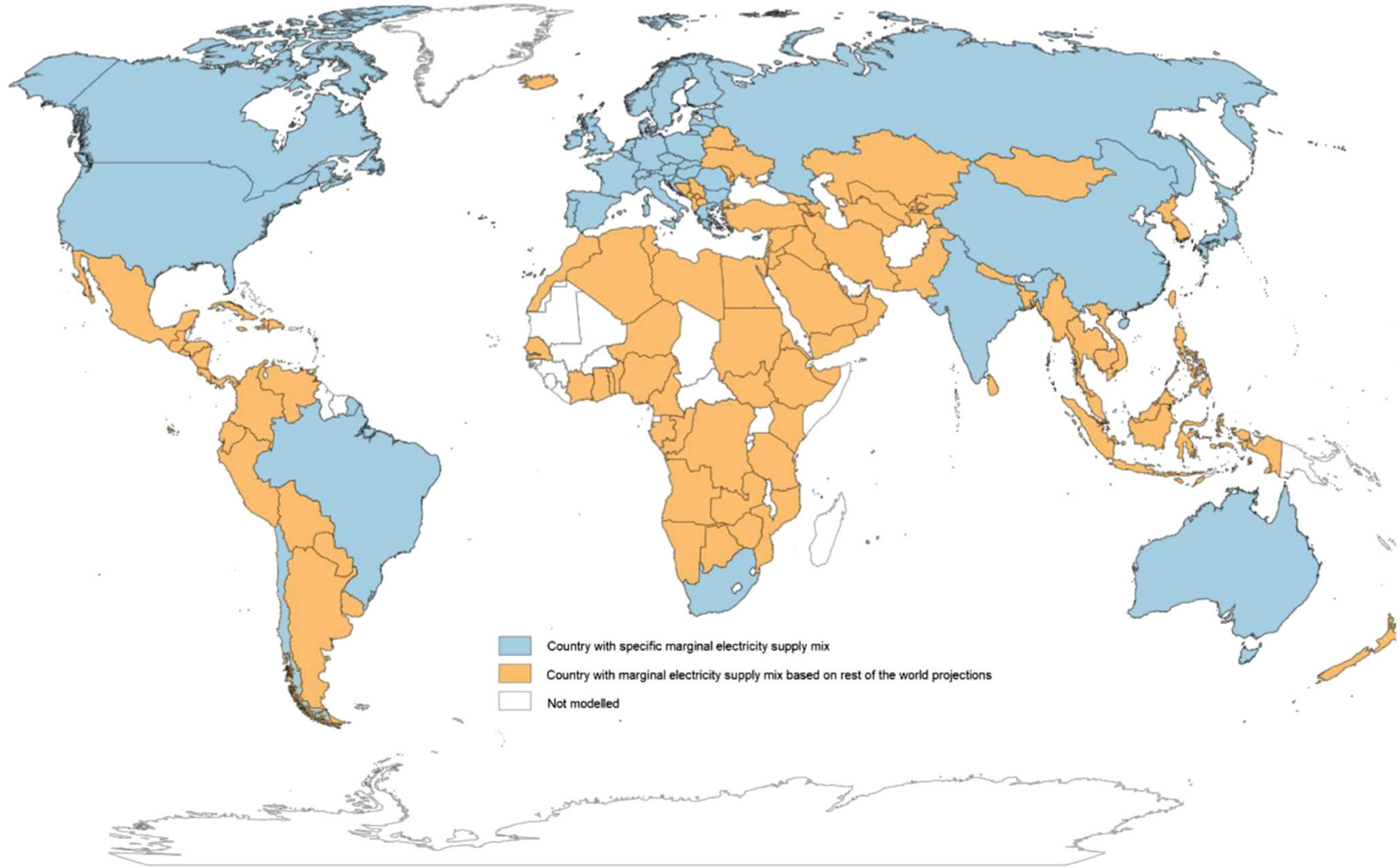

Fig. 1 Geographical coverage of the marginal electricity supply mixes in the consequential system model of ecoinvent v3.4, differentiated between countries where specific energy projections were used as a source of data and countries where rest of world shares were assumed

implemented. The share of each technology is based on the difference in production between the time of decision and the prospective time horizon, instead of their current production volumes. The identification of constraints relies on the energy system modeling work that is behind every scenario used in this work. Indeed, to create plausible energy system pathways, these frameworks compiled the technical, political, and geographical constraints, as well as the projected future power demand. No additional constraints are integrated ex-post to avoid interfering with the energy modeling work and to facilitate traceability.

\subsection{Market mix/impact assessment calculations and comparative analysis}

The following analyses are limited to the markets for which country-specific marginal mixes were calculated and to the overall RoW market. The individual countries using the RoW market composition are not assessed. The evaluation of the markets is performed at the low-voltage level and subregional markets from a country are analyzed as one entity designated by the name of the country-region since their marginal mixes are identical.

The marginal mixes are first examined individually with regard to their technological compositions and environmental impacts. The environmental impacts of the marginal mixes are calculated per $\mathrm{kWh}$ of net low-voltage electricity supplied using the Brightway2 LCA software framework (Mutel 2017).

A total of nine midpoints impact categories and one endpoint indicator are assessed:

- Climate change: the IPCC Global Warming Potential (GWP) characterization factors with a time horizon of 100 years, as implemented by the ecoinvent center (Stocker et al. 2013; Wernet et al. 2016).

- A set of midpoint categories from the ReCiPe 2008 Midpoint $(\mathrm{H})$ impact assessment method (Goedkoop et al. 2008). The selection of impact categories is based on the work by Gibon and colleagues (Gibon et al. 2017) in their assessment of low-carbon electricity supply options which are namely: freshwater ecotoxicity, freshwater eutrophication, human toxicity, metal depletion, particulate matter formation, photochemical oxidant formation, terrestrial acidification, and urban land occupation.

- Finally, the single score method ReCiPe 2008 Endpoint $(\mathrm{H}, \mathrm{A})$ is used to obtain the overall environmental performance of the different marginal electricity supply mixes in a single weighted and normalized indicator (Goedkoop et al. 2008). 
Life cycle impact assessment methods have several limitations such as missing characterization factors for certain substances, underlying value choices in the models, time and space aggregation and missing or poorly developed impact categories (Hauschild et al. 2013; Margni 2016). These shortcomings should be considered when examining and comparing the impact scores of the different marginal mixes as addressing them might modify the results and reduce or increase the difference between them.

These marginal mixes, as currently implemented in the consequential system model of ecoinvent v3.4 (i.e., as detailed in Section 2.1 and referred to as the third approach in the introduction), are then compared to several sets of alternative electricity supply mixes covering the same countries but calculated using different methodological choices or data sources. First, comparisons are made with the average mixes used in the attributional versions of ecoinvent v.3.4. Second, differences with the marginal mixes implemented in ecoinvent consequential v3.3 (referred to as the first approach detailed in the introduction) are highlighted. Third, using the approach selected in Section 2.1, temporal parameters of Eq. (1) are changed resulting in two versions of the marginal mixes: (a) the time-horizon is set to 2020 instead of 2030 and (b) the time-frame is moved forward in time, using 2030 as the reference year and 2040 as the time horizon (evaluating the stability of the marginal mixes across a different time frame). Finally, alternative energy scenarios are used to calculate the marginal mixes and evaluate the influence of the scenarios on the resulting marginal mixes (i.e., another variation of the approach from Section 2.1). This last sensitivity test is only performed for countries where WEO 2016 is used as a source of data to calculate the marginal mix (i.e., China, India, Brazil, South Africa, and Russia) since the other scenario sources generally provide only one pathway. The new energy policy scenario $^{7}$ and $450 \mathrm{ppm}^{8}$ IEA scenario from WEO 2016 is used to calculate the marginal electricity mixes instead of the current policies scenario (International Energy Agency 2016). For the third and the fourth comparisons, the Wurst python package was utilized to integrate alternative electricity marginal supply mixes in the ecoinvent database (Cox et al. 2018; Mendoza Beltran et al. 2018). This allows comparisons to be performed where the alternative mixes are not simply changed in the foreground, but also in the background of the database. This results in the creation of separate versions of the database labeled according to their order in the previous paragraph, as "Ecoinvent consequential v 3.4 (2015-2020)", "Ecoinvent consequential v 3.4 (2030-2040)", "Ecoinvent consequential

\footnotetext{
$\overline{7}$ The new policy scenario considers the pledges, intentions and targets announced by countries even though they might not be endorsed by any law.

${ }^{8} 450 \mathrm{ppm}$ corresponds to the scenario that is necessary to limit the average global temperature increase in 2100 to 2 degrees Celsius above pre-industrial levels.
}

v 3.4 (WEO new policy)" and "Ecoinvent consequential v 3.4 (WEO 450ppm)", respectively.

Comparative analyses are undertaken in terms of market compositions and environmental impacts. The comparison of the technological shares contained in the marginal electricity markets of ecoinvent consequential v3.4 and the alternative set of electricity mixes are compared using Eq. (2).

Change $=$ Share technology (i) marginal mix

ecoinvent consequential v.3.4-

Share technology (i) mix alternative (j)

where:

(i) is the electricity-producing technology

(j) alternative methodological choices or data sources to calculate the electricity mix

The comparisons of each alternative set of electricity mixes to the marginal mixes of ecoinvent consequential v3.4 are represented in Fig. 4 in separate subplots. The different subplots are box plots ${ }^{9}$ representing the distributions of the results obtained with Eq. (2). With regard to the environmental impact comparisons, the distributions of the impact results of each set of electricity mix are compared. These are represented in Fig. 5 under a boxplot representation where the different subplots are dedicated to a specific impact category.

Finally, notebook documents produced with the Jupyter Notebook application are used to detail the workflow behind the integration of alternative electricity market mixes and the data analysis processes (Kluyver et al. 2016). The notebooks are available in the electronic supporting information. They contain the python computer script used to manipulate Brightway2 and the Wurst python package and to perform the impact analysis. The alternative mixes are provided in the Electronic Supplementary Material contained in the folder "data" in the compressed file "SI.Notebooks.7z." In addition, as a spillover of this project, the prospective average electricity mixes for the year 2020, 2030, 2040 and 2050 are also provided. These can be used as a starting point to create a prospective version of the ecoinvent attributional databases. The mapping between the energy scenarios and the ecoinvent database follows the approach presented in the manuscript.

\section{Results}

The composition and the environmental impacts of the marginal mixes integrated into the ecoinvent consequential

\footnotetext{
${ }^{9}$ In the different boxplot representations, the bottom and top of the box represent the first quartiles and third quartiles respectively. The line inside the box corresponds to the median of the results. The lower limit whiskers correspond to the minimum and the upper limit whiskers represent the maximum. One key shortcoming of representing data in boxplots is that they accentuate the importance of the extreme observations of a distribution.
} 
database v3.4 are detailed in Section 3.1. The marginal mixes are then compared to several sets of alternative electricity supply mixes calculated using the different methodological choices or data sources, as defined in Section 2.2, namely: the average mixes (i.e., year 2014) part of the ecoinvent attributional database v3.4 in Section 3.2; the marginal mixes from the ecoinvent consequential database v3.3 in Section 3.3; the marginal mixes defined with varying time frame "20152020," "2030-2040" in Section 3.4; and finally marginal mixes varying the underlying energy scenarios in Section 3.5. In terms of illustration, Fig. 2 shows the composition of the marginal mixes integrated into ecoinvent consequential v3.4. and Fig. 3 shows the comparison of life-cycle emissions of $\mathrm{CO}_{2}$ equivalents per $\mathrm{kWh}\left(\mathrm{CO}_{2}\right.$-eq $\left./ \mathrm{kWh}\right)$ for the different sets of electricity mixes, apart from the set presented in Section 3.5 limited to mixes using WEO 2016 as a source of data. The effects of the methodological and data changes on the technological composition of the marginal mixes are displayed in Fig. 4 and on the impact scores in Fig. 5, also excluding the set detailed in Section 3.5. Finally, in Section 3.5, Fig. 6 displays the comparison of the composition marginal mixes from ecoinvent consequential v3.4 to marginal electricity supply mixes calculated with the new policy scenario and the $450 \mathrm{ppm}$ scenario from WEO 2016. The country codes of the countries represented in the different figures are available in the ESM (section S.I 6).

\subsection{Marginal electricity supply mixes: composition and impact assessment}

The composition of the marginal mixes integrated into the consequential system model of ecoinvent $\mathrm{v} 3.4$ and their environmental impacts are examined in this section.

As shown in Fig. 2, the marginal electricity supply mixes are comprised, on a global average, of 59\% from renewable energy sources (RES), 27\% from fossil-based sources and $14 \%$ from nuclear power. Among the RES, onshore wind turbines dominate with an average share of $21 \%$ of the total

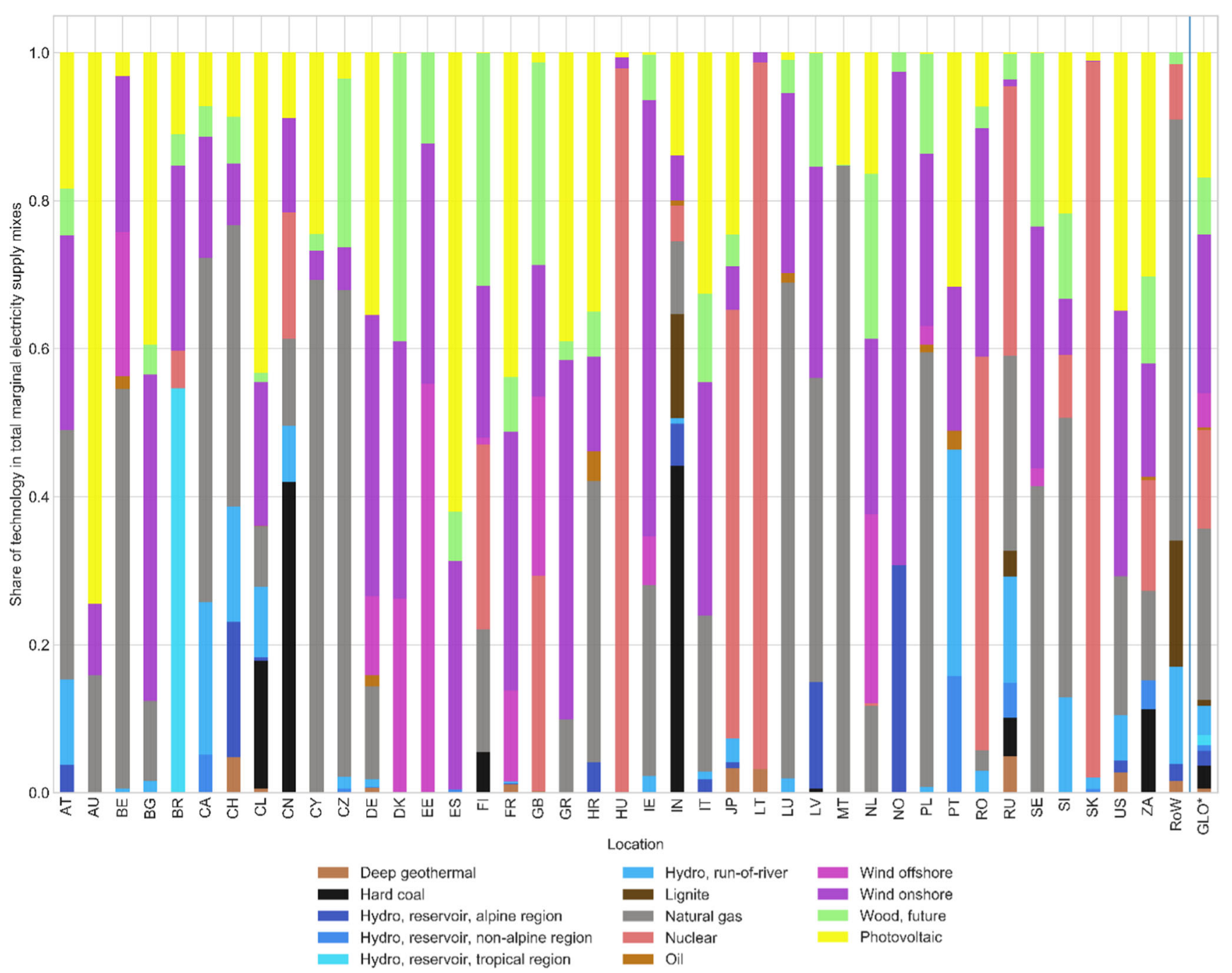

Fig. 2 Composition of marginal electricity supply mixes ecoinvent consequential v3.4 at the low voltage level per country and for RoW. Numerical values are available in the electronic supplementary material: "SI. Marginal mixes.xlsx". *GLO is the mean value of the different marginal mixes 


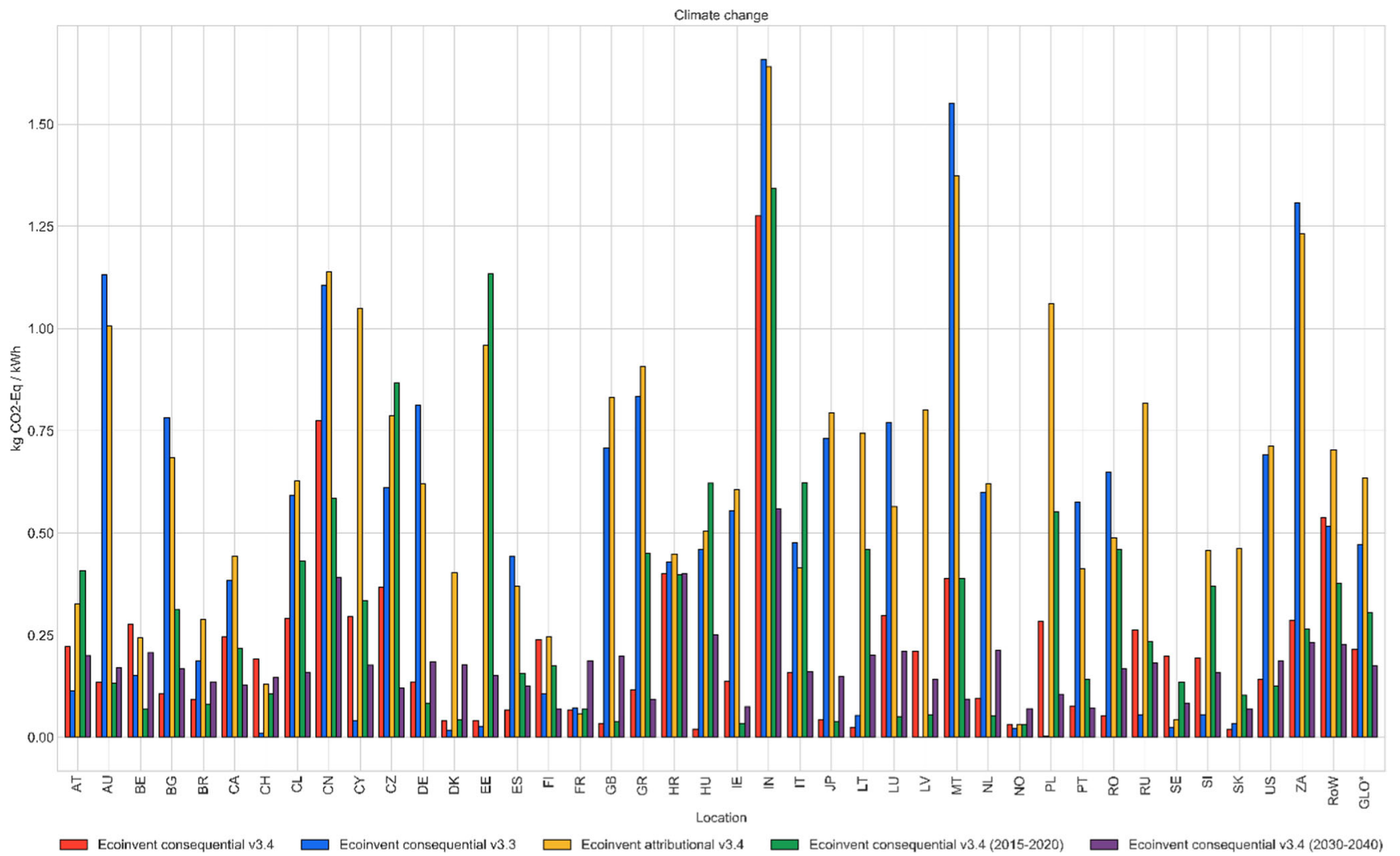

Fig. 3 Comparison of results for the climate change impact category (IPCC 2013, GWP 100a) of marginal electricity supply mix ecoinvent consequential v3.4, ecoinvent consequential v3.3, ecoinvent attributional v3.4 ("cut-off by classification"), ecoinvent consequential v3.4 (2015-

mix and are followed by solar power with $17 \%$. In terms of fossil-based energy, the natural gas combined cycle power plant is the largest marginal electricity source contributing, on average, $23 \%$ of the total mix, followed by electricity from oil-fired power sources with $3 \%$. The shares of the technologies in the marginal electricity supply mixes can differ significantly across different countries. In Denmark, Estonia, Spain, France, and Norway, RES account for $100 \%$ of the mixes. Fossil-based electricity represents more than $50 \%$ of the marginal electricity mixes in Belgium, Cyprus, Luxemburg, Malta, Poland, China, and India. Finally, nuclear power accounts for a share of above $90 \%$ in Hungary, Lithuania, and Slovakia and $60 \%$ in Japan.

With regard to the climate change category, the average life-cycle emission factor of the marginal mixes is $0.216 \mathrm{~kg} \mathrm{CO}$-eq $/ \mathrm{kWh}$ and the median value amounts to $0.158 \mathrm{~kg} \mathrm{CO}$-eq $/ \mathrm{kWh}$. As shown in Fig. 3, India has the highest emission factor with $1.275 \mathrm{~kg} \mathrm{CO}_{2}$-eq $/ \mathrm{kWh}$. This high score is mainly caused by the important role of hard coal and lignite-fired units in the Indian marginal mix, contributing $44 \%$ and $14 \%$ of the mix, respectively, and the fact that these power plants have very low conversion efficiencies, today. Slovakia has the lowest emission factor of $0.019 \mathrm{~kg} \mathrm{CO}_{2}$-eq/ $\mathrm{kWh}$. This score is explained by the composition of the
2020) and ecoinvent consequential v3.4 (2030-2040). Numerical values are available in the electronic supplementary material: "SI. Comparison environmental impacts of marginal mix.xlsx". *GLO is the mean value of the different marginal mixes

marginal mix of Slovakia where nuclear power accounts for $97 \%$, hydropower for $2 \%$ and solar and wind power providing the remainder. The Chinese marginal electricity supply mix shows a score of $0.774 \mathrm{~kg} \mathrm{CO}$-eq $/ \mathrm{kWh}$. The significant role of fossil fuel-fired units contributing $54 \%$ with hard-coal power plants accounting for $42 \%$ of the total mix largely explains this score. China has a lower emission factor than India due to the larger share of nuclear power accounting for $17 \%$ of the total mix in China and 5\% for India as well as the use of lignite-fired power plants as part of India's marginal mix which are not used in China. In the USA, the score obtained is $0.142 \mathrm{~kg} \mathrm{CO}{ }_{2}$ eq $/ \mathrm{kWh}$. This result stems from the significant share of RES representing $81 \%$ of the marginal electricity mix, with natural gas combined cycle power plants covering the remainder. The emission factor of Germany is similar with $0.136 \mathrm{~kg} \mathrm{CO}_{2}$-eq $/ \mathrm{kWh}$ with a mix composed of $86 \% \mathrm{RES}$ and $13 \%$ combined cycle natural gas power plants. Finally, for Switzerland, the climate change impact score equals $0.191 \mathrm{~kg} \mathrm{CO}$-eq $/ \mathrm{kWh}$ due to the $38 \%$ share of natural gas combined cycle power plants, the rest being covered by hydro sources, contributing $36 \%$, and a mix of wind, solar PV and bioenergy units.

With regard to the other impact categories, India has the highest scores in six out of nine of the categories (see results in 
a. Comparison of electricity mix shares of ecoinvent consequential v3.4 and attributional v3.4

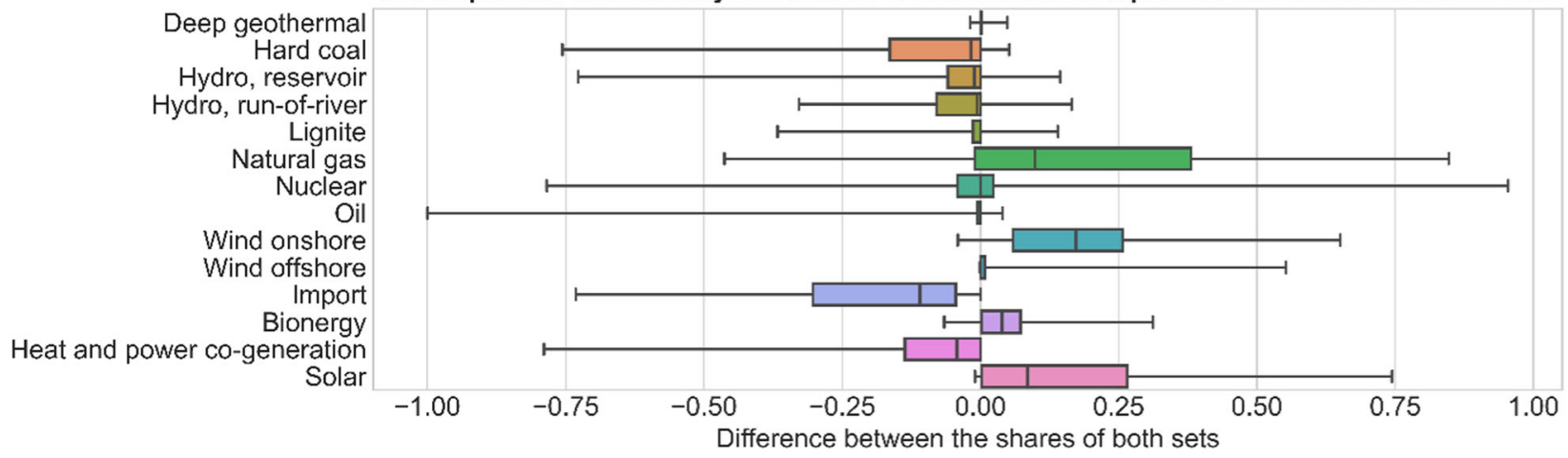

b. Comparison of electricity mix shares of ecoinvent consequential v3.4 and consequential v3.3

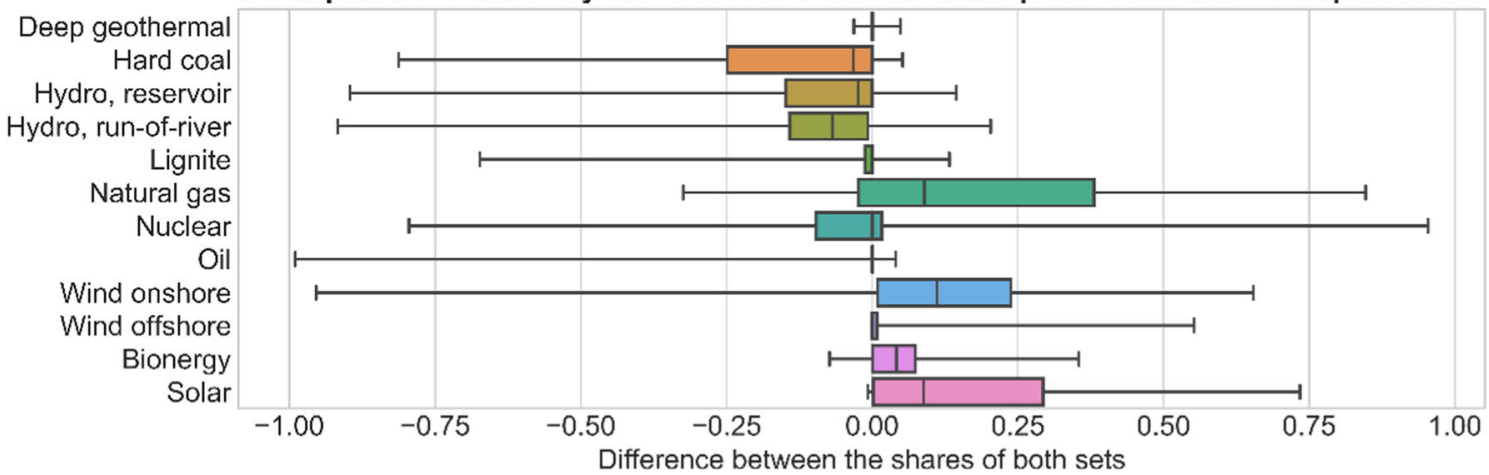

c. Comparison of electricity mix shares of ecoinvent consequential v3.4 and consequential v3.4 (2015-2020)

Deep geotherma

Hard coal

Hydro, reservoir

Hydro, run-of-river

Lignite

Natural gas

Nuclear

Oil

Wind onshore

Wind offshore

Bionergy

Solar

$-1.00$
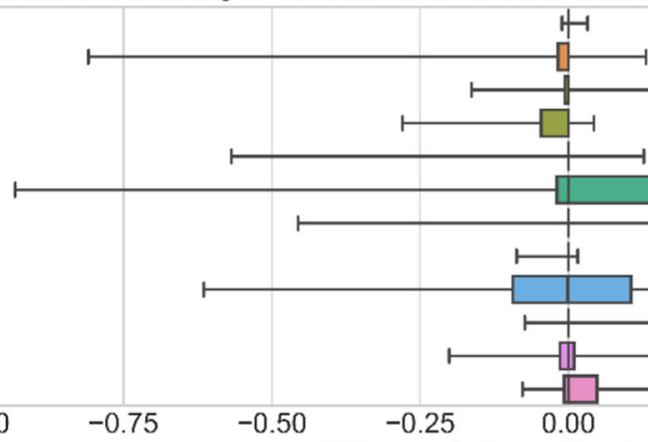

Difference between the shares of both sets

d. Comparison of electricity mix shares of ecoinvent consequential v3.4 and consequential v3.4 (2030-2040)

Deep geothermal

Hard coal

Hydro, reservoir

Hydro, run-of-river

Lignite

Natural gas

Nuclear

Oil

Wind onshore

Wind offshore

Bionergy

Solar
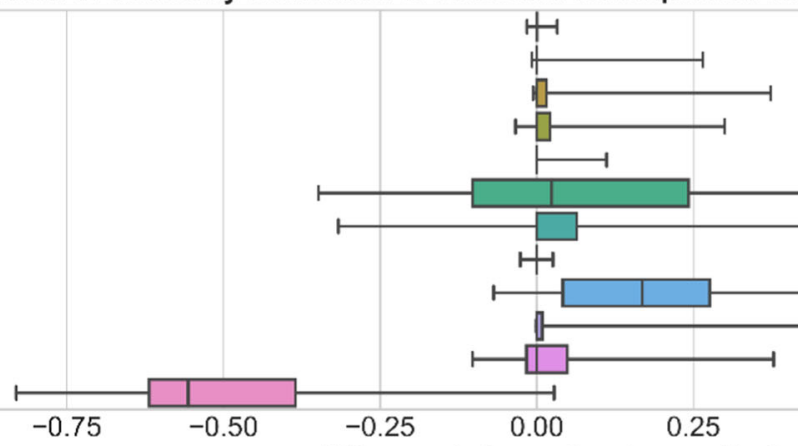

Difference between the shares of both sets

Fig. 4 Comparison of the compositions of marginal electricity supply mixes from ecoinvent consequential v3.4 using eq. (2) to a ecoinvent attributional v3.4, b ecoinvent consequential v3.3, c ecoinvent consequential v3.4 (2030-2040), and d ecoinvent consequential v3.4 (2015-2020) 

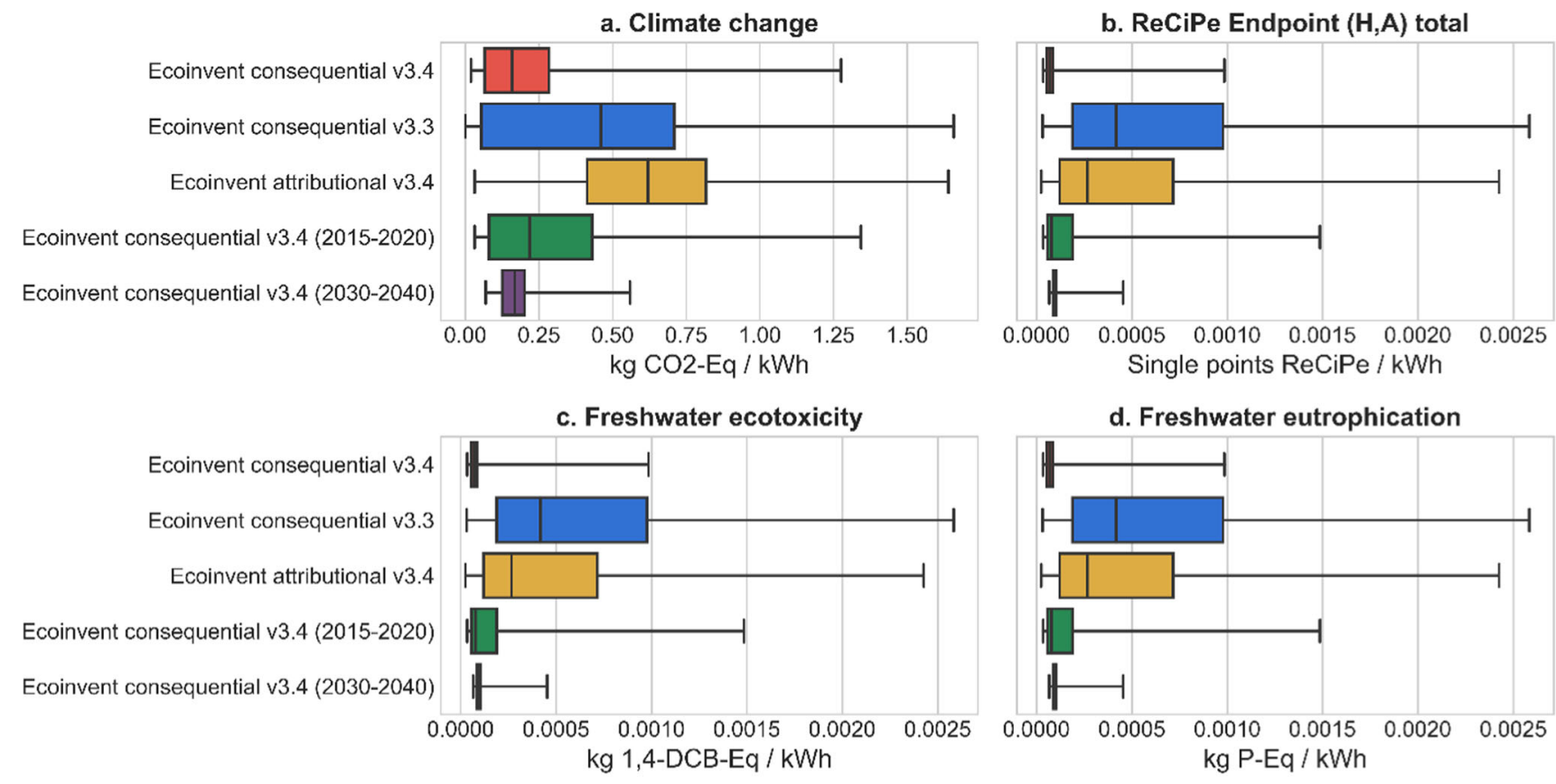

e. Human toxicity

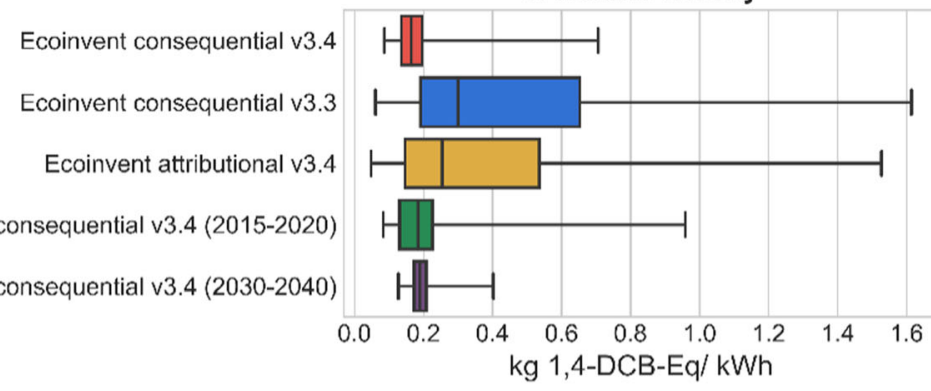

g. Particulate matter formation
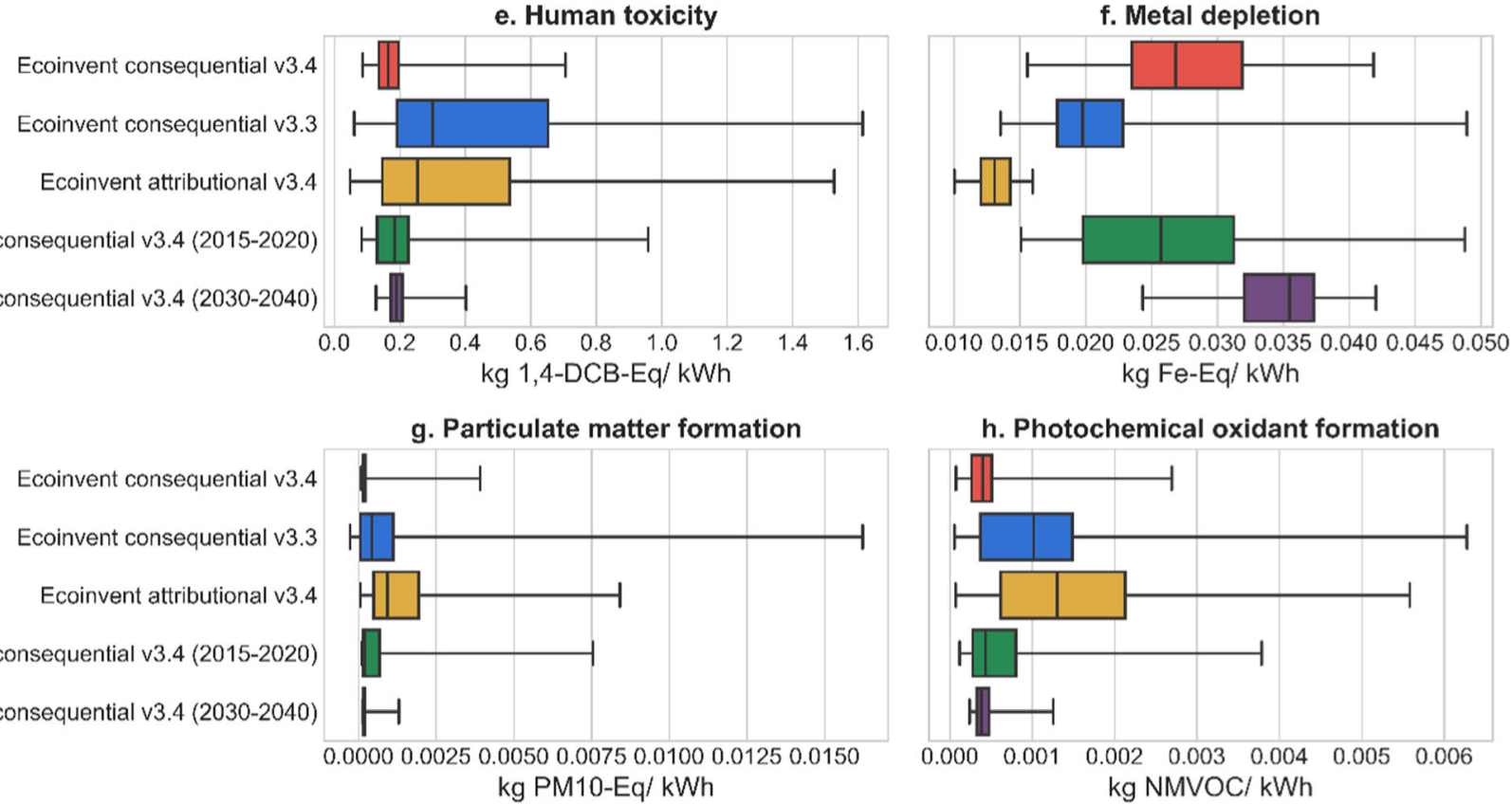

h. Photochemical oxidant formation

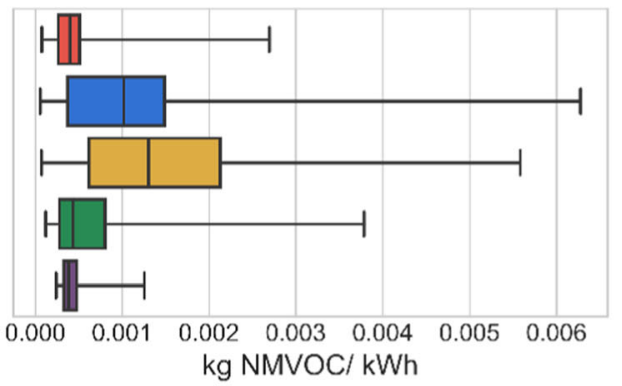

i. Terrestrial acidification

Ecoinvent consequential v3.4

Ecoinvent consequential v3.3

Ecoinvent attributional v3.4

Ecoinvent consequential v3.4 (2015-2020)

Ecoinvent consequential v3.4 (2030-2040)
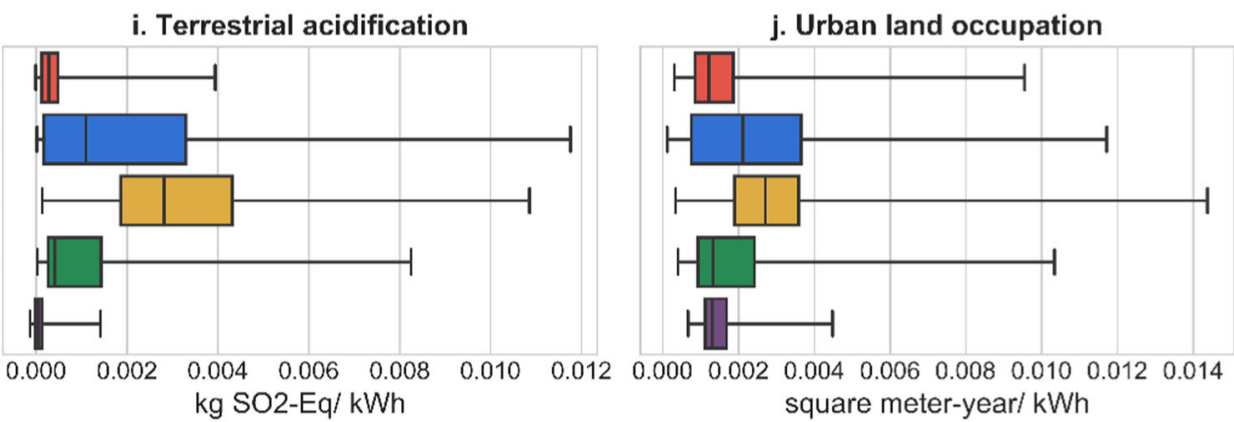

Fig. 5 Comparison environmental impacts marginal electricity supply mix ecoinvent consequential v3.4, ecoinvent consequential v3.3, ecoinvent attributional v3.4, ecoinvent consequential v3.4 (2030-2040), and ecoinvent consequential v3.4 (2015-2020) 


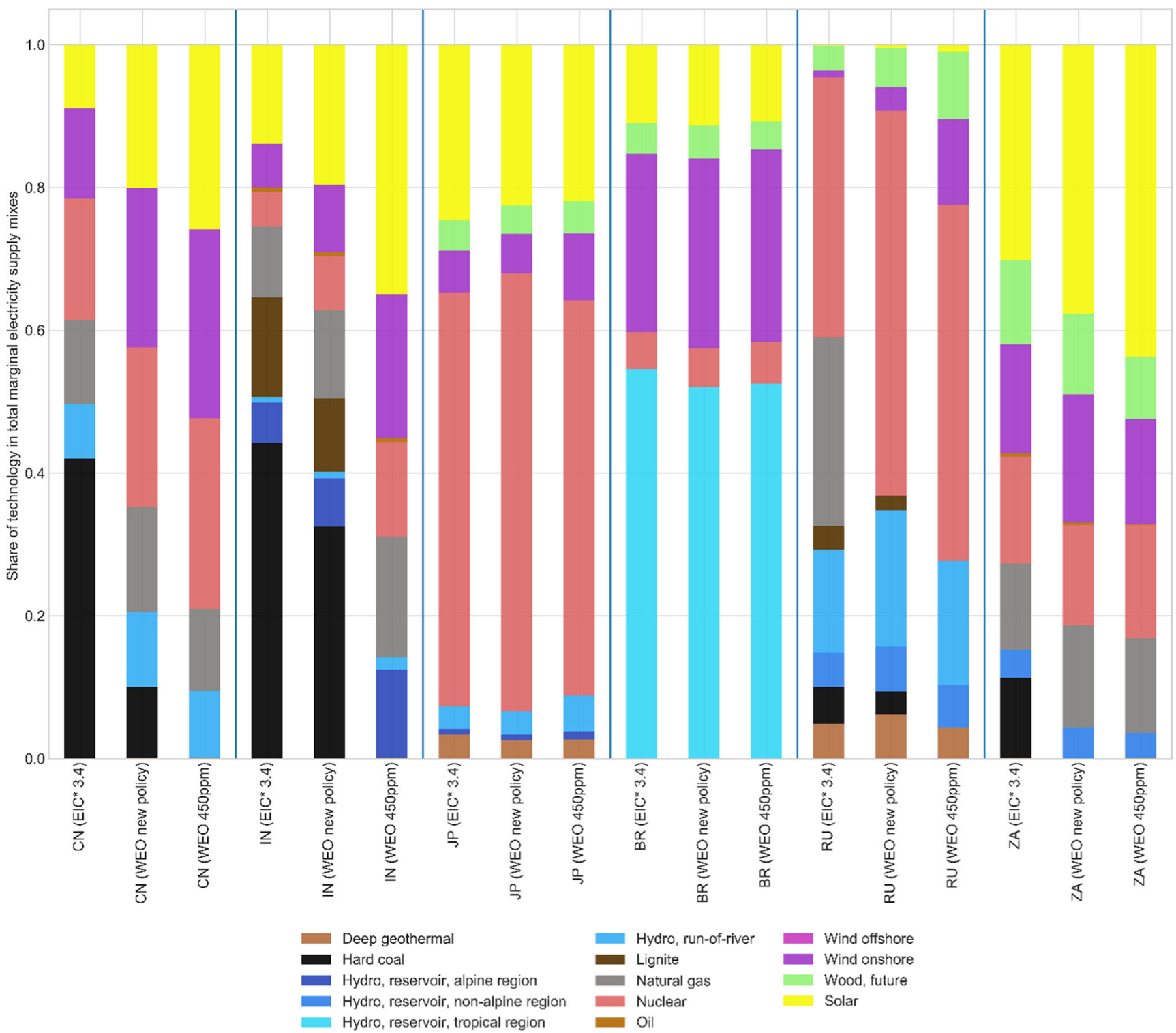

Fig. 6 Comparison of the composition marginal electricity supply mixes from ecoinvent consequential v3.4 (EIC 34) to marginal electricity supply mixes calculated with the new policy scenario and the $450 \mathrm{ppm}$ scenario

from WEO 2016. Numerical values are available in the electronic supplementary material: "SI. Marginal mixes.xlsx"

section S.I.3). This is mostly caused by the substantial contribution hard coal and lignite makes to the Indian marginal mix. Bulgaria and Germany have the highest score in terms of freshwater ecotoxicity. In this category, the harmful effects are caused by the mining processes related to the copper components used in solar and wind power which accounts for $83 \%$ of the total Bulgarian mix and $84 \%$ of the total German mix. The German and Bulgarian marginal mixes show the largest scores in the metal depletion category due to the important role of solar and onshore wind power, and the resultant consumption of copper and steel. Off-shore wind-power is also an important contributor but has a smaller impact per $\mathrm{kWh}$ due to a higher capacity factor and a longer lifetime than onshore turbines. Finally, Chile obtains the highest score in terms of particulate matter formation due to substantial particulate matter emissions stemming from hard-coal-fired power plants due, in turn, to the large proportion of these units that are currently not equipped with particulate matter filters.

\subsection{Comparison of marginal electricity mixes and average electricity mixes in ecoinvent v.3.4}

This section details the comparison of the marginal electricity mixes integrated into the ecoinvent consequential database v3.4 to the average mixes contained in the ecoinvent attributional databases v3.4. The technological compositions of the alternative electricity mixes are displayed in SI. 2 with 
numerical results available in the Electronic Supplementary Material: "SI. Marginal mixes.xlsx."

Figure $4 \mathrm{a}$ contains the distribution of the results obtained with Eq. (2) for the comparison of the composition of the average mix and the marginal mix. A distribution of the results represented in the positive side of the subplot indicates a technology with a larger share in the marginal mix than in the average mix, and vice-versa. As shown in Fig. 4a, the role of natural gas-fired units, wind onshore, bioenergy, and solar energy is growing significantly whereas traditional technologies such as hard coal, hydropower, and oil-fired units are decreasing in importance. In terms of average shares (Electronic Supplementary Material, "SI. Marginal mixes.xlsx"), comparing the averages mixes to the marginal mixes, natural gas grows from 7 to $23 \%$, wind onshore from 5 to $21 \%$, and solar from 1.5 to $17 \%$. The share of hard coal is reduced from 14 to $3 \%$, hydropower from 18 to $8 \%$, and oilfired units from 7 to $0.3 \%$. The imports and electricity from cogeneration units are not included in the marginal mix which explains why their distributions are entirely located on the negative side of the plot.

Comparisons of the impacts are displayed in Fig. 5 where each subplot corresponds to an environmental category and each line shows the distribution of the impacts across a different set of electricity supply mixes. The first line in each subplot corresponds to the electricity supply mixes integrated into ecoinvent consequential v3.4 and the following lines correspond to the mixes calculated using different methodological choices or data sources as detailed in Section 2.2. Figure 5 shows that the impacts of the marginal mixes are smaller than the impacts of average mixes in eight out of the ten midpoint and endpoints indicators assessed. The increased shares of RES and of natural gas combined cycle plants explain the tendency towards lower impact scores. The impacts of the average electricity mix are generally more spread out in comparison to the marginal mix. This is due to the extreme value caused in some categories by harmful fossil-fired units whose shares are larger in the average mixes.

In terms of climate change, the average electricity mixes have an average emission factor of $0.472 \mathrm{~kg} \mathrm{CO}_{2}$-eq $/ \mathrm{kWh}$ and a median value of $0.460 \mathrm{~kg} \mathrm{CO}$-eq/ $\mathrm{kWh}$, and the marginal mixes have an average of $0.216 \mathrm{~kg} \mathrm{CO}{ }_{2}$-eq $/ \mathrm{kWh}$ and a median of $0.158 \mathrm{~kg} \mathrm{CO}$-eq $/ \mathrm{kWh}$. India has the maximum scores for both the average and the marginal mixes, with emission factors of $1.640 \mathrm{~kg} \mathrm{CO}$-eq/kWh and $1.275 \mathrm{~kg} \mathrm{CO}$-eq $/ \mathrm{kWh}$, respectively. The biggest difference between average and marginal mix, in terms of impacts, occurs in Lithuania with an emission factor of $0.022 \mathrm{~kg} \mathrm{CO}_{2}$-eq $/ \mathrm{kWh}$ for its marginal mix and of $0.745 \mathrm{~kg} \mathrm{CO}_{2}$-eq $/ \mathrm{kWh}$ for its average mix. The score of the average mix is mostly due to the $73 \%$ share of imports coming from Belarus and Russia, with both relying on fossilfired units for a large share of their mix, and a $12 \%$ share stemming from fossil heat and power co-generation units.

\subsection{Comparison marginal electricity mixes ecoinvent consequential v3.4 and v3.3}

The marginal electricity mixes from the consequential system models of ecoinvent v3.3 and v3.4 are compared in this section. The different approaches used in v 3.4 and before lead to differences in terms of market compositions as shown in Fig. 4b. In ecoinvent v3.4, in comparison to v.3.3, the average share of natural gas grows from 7 to $23 \%$, of wind onshore from 13 to $21 \%$, and of solar energy 1 to $16 \%$. The average share of hard-coal-fired units decreases from 16 to $3 \%$, of hydropower from 32 to $8 \%$, and of nuclear power from 16 to $13 \%$. In version 3.3 , the definition of the mixes was largely guided by the constraint identification step since the ecoinvent marginal linking algorithm was largely ineffective, as detailed in Section 2.1.4, and the shares were based on the current annual production volumes. In some cases, the constraints moderately influence the composition of the markets and the resulting marginal mixes were very similar to the average mixes. For example, in Chile, oil-fired technology, accounting for less than $10 \%$ of the average mix, was the only constrained electricity sources or, in South Africa, imports were the only constrained source contributing less than $5 \%$ of the average mix. In other cases, constraints had a large influence on the market mix definition. In Estonia, peat and oil-fired sources and imports accounted for almost $80 \%$ of the average mix and were excluded from marginal mixes to the benefit of wind which represented $82 \%$ of the marginal mix despite accounting for less than $5 \%$ share in the average mix. Similar trends can be observed in countries such as Russia and Slovenia.

In relation to the impact scores presented in Fig. 5, the spread was wider for the marginal mixes in v3.3 than for the marginal mixes in v3.4. For the markets where environmental constraints (e.g., peat-fired sources were excluded in v3.3) played a significant role in determining the mix composition, the impacts tended towards lower scores, that could even be smaller than their equivalents in v3.4. Nevertheless, the influence of these constraints was often moderate, resulting in most cases in marginal mixes in v3.3 very similar to their corresponding average mixes, and obtaining higher scores than the marginal mixes from $v 3.4$.

\subsection{Comparison of different time-frame}

Alternate versions of the marginal electricity mixes are calculated by varying the time parameters used in Eq. (1). Firstly, the time horizon is reduced to 2020 and secondly, the reference year and the time horizon are changed to 2030 and 2040, respectively. The effects of this change on the composition of markets are displayed in Fig. 4, on the impact scores in Fig. 5, and on the global warming potential per country in Fig. 3.

In the first case, as shown in Fig. $4 \mathrm{c}$, the average share of hard coal-fired units grows from 3 to $7 \%$ and the share of run- 
of-river power plants from 4 to $7 \%$. The role of solar power decreases from an average share of 16 to $12 \%$. This leads to a shift of the impact results' distribution towards higher scores in eight out of the ten categories assessed as presented in Fig. 5. In terms of climate change, the average score is increasing from 0.216 to $0.306 \mathrm{~kg} \mathrm{CO}$-eq/ $/ \mathrm{kWh}$ and the median value from 0.159 to $0.219 \mathrm{~kg} \mathrm{CO}$-eq/ $/ \mathrm{kWh}$. The largest increase occurs in Hungary with an original score of $0.020 \mathrm{~kg} \mathrm{CO}_{2^{-}}$ $\mathrm{eq} / \mathrm{kWh}$ rising to $0.621 \mathrm{~kg} \mathrm{CO}$-eq/ $/ \mathrm{kWh}$. This increase can be explained by the large variations of electricity production from natural gas-fired units between the year 2015 and 2030 . Indeed, Hungarian electricity produced from natural gas is growing from a production of $3382 \mathrm{GWh} /$ year in 2015 to $9557 \mathrm{GWh} /$ year in 2020 and falls to $2219 \mathrm{GWh} /$ year in 2030 (European Commission 2016). This results in the absence of natural gas-fired units in the marginal mix when the time horizon is 2030 and a $90 \%$ contribution when it is 2020 .

In the second case, the average share of solar power across the different markets grows from 17 to $65 \%$ as shown in Fig. $4 \mathrm{~d}$. This change occurs mainly at the expense of wind power whose average share is shrinking from 21 to $5 \%$ and of natural gas combined cycle units, the contribution of which decreases from 23 to $16 \%$. As shown in Fig. 5, the spread of the impact results across the different markets is decreasing for all the categories due to marginal mixes being uniformly dominated by solar power. Indeed, solar units have shares in the marginal mixes that are above $60 \%$ in all of the markets, apart from Croatia where it contributes $35 \%$ of the total mix. This does not lead to large reductions in the impacts as the switch is achieved with a change from a mix of technologies with moderate impacts. In the climate change category, the average score is decreasing by $19 \%$ from 0.216 to $0.176 \mathrm{~kg} \mathrm{CO}_{2}$-eq/ $\mathrm{kWh}$ and the median is increasing by $6 \%$ from 0.159 to $0.168 \mathrm{~kg} \mathrm{CO}_{2}$-eq $/ \mathrm{kWh}$. Moreover, the average and the median impact scores for the metal depletion category increase by $26 \%$ and $32 \%$ respectively, mostly due to the growth of solar power. Some slightly negative impact scores are to be mentioned in the terrestrial acidification category which are related to the important role of solar power and an error in the LCI of one of the components of this technology. There is an inconsistency ${ }^{10}$ in the amount of primary silver used in the upstream lifecycle of the process "inverter production, $2.5 \mathrm{~kW}$ ", and the recycled silver recovered from the generic (i.e., non-specific to the inverter) waste treatment processes for electronics scrap used downstream. The use of generic processes for waste recovery causes the amount of silver recycled, and substituting a virgin equivalent, to be greater than the amount of primary silver involved in the inverter production. Hence, this creates incorrect negative scores in this category where silver plays an important role.

\footnotetext{
${ }^{10}$ The ecoinvent center has been informed about this issue
}

\subsection{Comparison regarding different scenarios for the projections}

The effect of scenarios on the composition of marginal mixes is presented in Fig. 6 and the corresponding effects in terms of environmental impacts in Fig. SI.4.1 (Electronic Supplementary Material). The current policies' scenario, used as a source of data for the update of the mixes in the ecoinvent database, is the most conservative of the three scenarios available in the WEO 2016 in terms of decarbonization, with $450 \mathrm{ppm}$ being the most ambitious, and with the new policies presenting an intermediate outcome.

The changes in the underlying scenario lead to changes in the composition of the marginal mixes. These changes are in line with the scenarios, namely the more ambitious the scenario, the more decarbonized the resulting marginal mixes will be. In Fig. SI.4.1 (Electronic Supplementary Material), in six out of the ten impact categories, the use of a decarbonized scenario to define the marginal mix results in lower impacts per $\mathrm{kWh}$. In the climate change category, the average score of the six markets with alternative scenarios available decreases by $78 \%$, from $0.456 \mathrm{~kg} \mathrm{CO}_{2}$-eq $/ \mathrm{kWh}$ in the current policies scenario to $0.278 \mathrm{~kg} \mathrm{CO}_{2}$-eq $/ \mathrm{kWh}$ in the new policies scenario and to $0.102 \mathrm{~kg} \mathrm{CO}$-eq $/ \mathrm{kWh}$ in the $450 \mathrm{ppm}$ scenario. The median decreases by $61 \%$, following the same order, from 0.275 to 0.126 and to $0.108 \mathrm{~kg} \mathrm{CO}_{2}$-eq $/ \mathrm{kWh}$. The maximum difference is observed in India with a decrease of $86 \%$ due to the switch from hard coal to energy sources with lower carbon intensities. The smallest difference occurs in Brazil with a 5\% reduction, due to an original marginal mix already highly decarbonized in terms of direct emissions. Regarding metal depletion, the average scores increase by $19 \%$ and the mean by $24 \%$ which can be explained by the growth in metal intensive technologies such as solar and wind power. The largest increase of the metal depletion score occurs in India with 39\% and the smallest increase occurs in Japan with $1 \%$ where the mix is stable across the scenarios.

\section{Limitations}

Projections from different energy system modeling families are used to obtain a large geographical coverage. This comes at the cost of mixing different and sometimes inconsistent assumptions and methodological choices made in the various energy scenarios. The use of consistent storylines across the scenarios was used as a solution to mitigate this issue as a single source providing global energy scenarios at a country level does not yet exist. Another source of inconsistency exists between the modeling choices from the energy scenarios and the LCI database. Disaggregation of technological and geographical classifications is performed as a first step to reconcile the LCI data and the energy scenarios. Nevertheless, these 
disaggregations are imperfect and should be improved, as detailed in Section 2.1.2 and in the last three paragraphs of this section. Moreover, harmonization of the technologies (e.g., use of harmonized performance parameters and emissions factors, and further disaggregation) present in both entities should be undertaken as a next research step. Furthermore, the use of current average electricity generation datasets might introduce an error in the representation of future generation technologies that will be installed as a result of changes in demand. Therefore, LCI modeling of future power generation technologies would be relevant avenues of future work that would increase the accuracy of the results.

The calculation of the marginal electricity mixes relies on prospective models which are inherently uncertain and imperfect. Several scenarios are based on cost optimization of the energy system which is not always representative of realworld decision-making processes (Astudillo et al. 2018; Vandepaer and Gibon 2018). Moreover, most long-term energy models have time resolutions which are too low to properly capture the production from VRES and their increasing role in the energy sector (Krakowski et al. 2016; Astudillo et al. 2017; Vandepaer and Gibon 2018). Finally, the transparency and reproducibility of such models are frequently questioned as they are, in most cases, not open to public scrutiny (Pfenninger et al. 2014). Therefore, it is relevant to investigate different pathways and compare different modeling approaches when building new marginal mixes and evaluating how they can influence the results. Furthermore, the marginal mixes can be sensitive to several choices which should be adjusted to the goal and scope of a specific study. For that purpose, the notebooks provided in the Electronic Supplementary Material allow LCA researchers to reproduce the workflow necessary to integrate their own marginal electricity mixes at the background database level, varying the scenarios or other elements involved in the marginal mixes calculations.

Long-term marginal electricity supply mixes are considered to provide an aggregated representation of the effects of short-term changes in demand for electricity (i.e., operational dynamics) on the installation and generation of new generation capacities and their generation. Nevertheless, the operational short-term effects can deviate largely from the longterm effects and should not be used interchangeably as substitutes (Amor et al. 2014). Furthermore, the relationship between short-term and long-term effects might become more complex with the increased penetration of intermittent RES. The integration of operational dynamics at the scale of an LCI database is a challenging issue and was not addressed in this work. In an individual LCA study, LCA practitioners should evaluate the role of short-term dynamics on their results. The combination of short-term and long-term effects in a single LCA model is a possible option and could be captured with tools such as energy system models in a prospective way or in a retrospective way using historical data. Finally, CLCA aims to include all processes reacting to a decision. Nevertheless, marginal mixes, as they are calculated in this work, do not incorporate any other effects that may accompany or result from the changes in the installed capacity. Indeed, other indirect effects such as infrastructure changes caused by increased VRES or effects resulting from changes in energy prices caused by the integration of certain types of technologies are not incorporated in the marginal mixes. CLCA practitioners should verify the presence of additional indirect effects and include them within the system boundary when relevant.

It is important to highlight several limitations specific to the technology mapping step which should be addressed in future research work or when adequate data become available. Firstly, the disaggregation of the different technologies is based on current average market shares which do not capture the extent to which each technology subset is able to react to a change in demand. Trend analyses comparable to the work performed at the scenario level using Eq. (1) should also be realized for each technology subset. Secondly, additional data should be collected to disaggregate certain technologies currently relying on one-to-one matching. This would allow for possible differences between the technologies currently represented by the same LCI dataset to be evaluated. For example, the choice of the "Photovoltaic, 3kWp slanted-roof installation, multi-Si, panel, mounted" dataset to represent all solar technologies is probably not entirely representative of the impacts of several solar installations regrouped under the single solar designation in the energy scenarios. Indeed, this solar LCI dataset represents a reduced size rooftop installation whereas the solar category contained in the energy scenarios might also include large-scale installations and thereby misses possible scaling relationships and the differences with openground installations (Caduff et al. 2011).

Another limitation related to the matching step, with more substantial impacts on the results, is that electricity imports are not considered in the composition of the marginal electricity supply mixes as international electricity trade is not detailed in the energy scenarios used for this work. Some countries currently rely on electricity generated outside their borders for a large share of their supply and are likely to meet additional demand needs with imports as well. This constitutes a significant difference with the attributional versions of the ecoinvent database where imports are part of the markets for electricity. Combined heat and power (CHP) units are usually excluded from the marginal electricity mixes as heat is considered as the determining co-product and electricity the constrained byproduct, hence changes in the demand of electricity do not lead to the installation of new CHP units (Consequential-lca 2015b). Nevertheless, results from public energy scenarios are too aggregated to provide a differentiation between $\mathrm{CHP}$ sources and single output sources, and thus it is likely that electricity production coming from CHP units were not excluded, in reality. 
Finally, all generation technologies are modeled based on currently available technologies. Nevertheless, marginal electricity supply mixes aim to reflect the effect of a change in demand for electricity today on the installation of generation capacity that will enter into service at a future time horizon. Electricity generation technologies that will be operational at this time horizon might have a better or worse environmental performance than the currently modeled technologies. Furthermore, new types of technologies, still at an experimental level today, are projected to be integrated into the supply mixes in the future. However, the identification of the technological composition of the marginal mix was prioritized as it was assumed to have a greater influence on the life cycle impact assessment (LCIA) results of the marginal mix than changes in the generation technologies which should be addressed at a next research step.

\section{Discussion}

This study applies a pragmatic methodology, at the scale of a CLCI background database, providing a compromise between accuracy and straightforward execution. It would be beneficial to the field of CLCA to replicate this approach to other sectors in the ecoinvent database. Extending this work to other areas should be carefully tested as this method has been sometimes described in the literature as too simplistic and unable to capture certain complex dynamics (Mathiesen et al. 2009; Buyle et al. 2018). Furthermore, it is dependent on the availability of scenarios describing the future states of each specific sector which are, in many cases, not available. Nevertheless, additional promising approaches have been proposed in the literature to identify marginal suppliers and affected processes that could be more appropriate. Causal descriptive models were recommended to identify affected processes in the agricultural or bio-based sector due to the complex interrelations between the environmental, social and economic dimension involved in this field (De Rosa et al. 2016). Furthermore, trade-based methods are another possible option which has been discussed in the case of bananas, Portland cement and wood (Pizzol and Scotti 2017; Sacchi 2018). The identification of the marginal suppliers and of the affected processes should be tailored to each sector based on the availability of data and on the forces that define them.

LCA practitioners and researchers must be aware of the reality of using a CLCI background database. They should examine how these aspects affect the result of their study and perform the required adjustments, as well as ensure that the assumptions underlying the background database correspond to the goal and scope of their study. Attempts to build CLCI databases are necessarily imperfect as they aim to capture all causal connections and interactions involved within and between the different spheres of human society and natural systems. Consequential studies and databases have relied on a large variety ${ }^{11}$ of external tools to substantiate the identification of marginal suppliers and affected processes. These approaches all come with a number of simplifications given the difficulty of the task at hand (Majeau-Bettez et al. 2018; Vandepaer et al. 2018). For example, economic models, which are often associated with CLCA and are behind most of the energy scenarios used in this work, face different shortcomings, including insufficient representation of future technologies, lack of transparency, difficulty to evaluate uncertainty, reliance on perfect competition assumption and the inability to capture certain non-economic elements (Marvuglia et al. 2013; Zamagni 2013; Menten et al. 2015; Wikipedia 2016; Frischknecht et al. 2017). The consequential system model of the ecoinvent database was built to reflect long-term consequences of small-scale decisions. The long-term perspective requires that the technology acting as a marginal supplier is the one that can adapt their level of production to long-term changes in demand. In the calculation of the marginal mixes provided in this work, this has the consequence that they are dominated by RES and natural gas power and cause smaller environmental impacts in most categories than current average mixes. Therefore, an incorrect use of the database, particularly in studies with a short-term perspective, might lead to significant underestimations of the impacts. Moreover, the limitation to small-scale aspects implies that possible feedback on the market parameters, or on the broader system caused by the studied changes, are not evaluated (Weidema et al. 2013; Roux et al. 2017). These effects may influence the dynamics of the systems under scrutiny and modify marginal technologies. For example, the results of this work could cause an increase in the demand for electricity due to the perceived lower impacts of the marginal mixes requiring the installation of units from alternative sources. One possible approach capturing large-scale feedback at the case study level is to integrate the relevant changes and interrelations in an energy system model or in an integrated assessment model (i.e., detailed as the second approach in the introduction section). Substitution, which is used systematically to handle multifunctionality in CLCA, relies on one-to-one ratios that are revealed to be inaccurate (Chalmers et al. 2015; Vadenbo et al. 2017). This issue stems from the linearity assumption generally applied in the field of LCA and could be lifted with the introduction of elasticities to characterize the substitution and supply links between products (Frischknecht et al. 2017; Yang and Heijungs 2018b). Nevertheless, it remains unclear how to implement this option at the scale of an LCI database. CLCI databases involve generalizing patterns in order to

\footnotetext{
${ }^{11}$ As listed in (Vandepaer et al. 2018), examples of these are: statistical/trend analysis on national statistics; trade data, or market projections; literature review; expert judgment; partial and general equilibrium models; agent modeling; game theory; experience curves; technology choice model; trade network analysis; to causal descriptive models.
} 
model chains of consequences and provide linking rules applicable to a broad set of cases. Consequently, these generalizations are not fully representative of the cause-effect relations at play in each specific situation. Finally, questions have been raised about the reproducibility of the consequential system model behind the ecoinvent database, as many of the assumptions used to link the datasets are not available or difficult to trace back (Boubault et al. 2017).

\section{Conclusions}

Consistent and accurate data for electricity supply are integrated into a consequential database providing a strong base for the development of consequential LCA. The methodology adopted in this version of the database avoids several shortcomings which existed in the approach used in the previous releases which led to unrealistic marginal mixes in several countries. The use of energy scenarios allows for the accounting of the evolution of the electricity system in the definition of the marginal mixes. The replacement of the linking algorithm by a procedure performed outside the database makes the marginal mixes more transparent and more easily verifiable and reproducible by LCA practitioners. Indeed, the methodology employed to calculate the marginal mixes is explained extensively in this article, with a detailed mapping of mainstream energy outlooks to the ecoinvent database and the notebooks specifying the computer scripts behind the manipulation of the different tools being provided. Finally, the key modeling choices involved in the calculations of the marginal mixes are assessed and allow an understanding of their influence on the results.

RES have the highest growth rates of any electricity generation source and dominate, on average, the marginal mixes. Despite the general dominance of RES in many of the markets represented, the comparison results show that there are important variations in the technological compositions of the marginal mixes as well as in their environmental impacts. Markets with a high share of RES generally have low impact scores in terms of climate change, whereas they cause large impacts in the metal depletion category. The comparison of the marginal mixes from ecoinvent v3.4 and electricity mixes calculated using alternative modeling choices reveals substantial differences. In most of the categories, average mixes (i.e., implemented in the attributional version of ecoinvent v3.4) result in higher impact scores than marginal mixes due to the substantial growth rates of RES. As previously shown by Weidema (2017), this also demonstrates the importance of properly selecting between an attributional or the consequential version of the database, especially given the central role of electricity in LCA. Furthermore, the changes in the methodology, the time parameters, and the underlying energy scenarios are all elements that can also lead to large differences in the results.
The time frame and the scenario should be in line with the goal and scope of the study, and their influence on the results evaluated via sensitivity analyses. The identification of the marginal processes in CLCA has not yet achieved methodological consensus. This is a pressing problem that needs to be addressed to strengthen the role of CLCA in decision making.

Acknowledgements The authors wish to acknowledge the contribution of fellow researchers who assisted by collecting a wide variety of energy scenarios. The authors would like to thank David Hudson for proofreading a preliminary version of this document and the staff at the ecoinvent center for their assistance integrating the new data into the database.

Funding information The authors received financial contribution from Wallonie-Bruxelles International (WBI) through the WBI-World Excellence Scholarship, and from the Natural Sciences and Engineering Research Council of Canada through the Discovery Grants Program. This work was partially funded by the Commission for Technology and Innovation in Switzerland (CTI) within the Swiss Competence Center for Energy Research in Heat and Electricity Storage (SCCER-HaE), contract number 1155000153, and the Swiss Competence Center for Energy Research in Supply of Electricity.

Open Access This article is distributed under the terms of the Creative Commons Attribution 4.0 International License (http:// creativecommons.org/licenses/by/4.0/), which permits unrestricted use, distribution, and reproduction in any medium, provided you give appropriate credit to the original author(s) and the source, provide a link to the Creative Commons license, and indicate if changes were made.

Publisher's note Springer Nature remains neutral with regard to jurisdictional claims in published maps and institutional affiliations.

\section{References}

Amor B, Gaudreault C, Pineau P-O, Samson R (2014) Implications of integrating electricity supply dynamics into life cycle assessment: a case study of renewable distributed generation. Renew Energy 69: 410-419

Astudillo MF, Treyer K, Bauer C, Pineau PO, Amor MB (2017) Life cycle inventories of electricity supply through the lens of data quality: exploring challenges and opportunities. Int J Life Cycle Assess 22:374-386

Astudillo MF, Vaillancourt K, Pineau P-O, Amor B (2018) Integrating energy system models in life cycle management. In: Benetto $\mathrm{E}$, Gericke K (eds) Designing sustainable technologies, products and policies: from science to innovation. Springer, Luxembourg

Boubault A, Kang S, Maïzi N (2017) Closing the TIMES integrated assessment model ( TIAM-FR ) raw materials gap with life-cycle inventories To cite this version : HAL Id : hal-01652739 Closing the TIMES integrated assessment model ( TIAM-FR ) raw materials gap with life-cycle inventories

Brandão M, Martin M, Cowie A et al (2017) Consequential Life Cycle Assessment: What, How, and Why? In: Abraham MA (ed) Encyclopedia of Sustainable Technologies. Elsevier Inc., pp 277-284

Buyle M, Anthonissen J, Bergh W Van Den (2018) Analysis of the Belgian electricity mix used in environmental life cycle assessment studies : how reliable is the ecoinvent 3.1

Caduff M, Huijbregts M, Althaus H, Hendriks J (2011) Power-law relationships for estimating mass, fuel consumption and costs of energy conversion Equipments. Environ Sci Technol 45:751-754 
Chalmers NG, Brander M, Revoredo-Giha C (2015) The implications of empirical and 1:1 substitution ratios for consequential LCA: using a $1 \%$ tax on whole milk as an illustrative example. Int J Life Cycle Assess 20:1268-1276

Confédération Suisse (2016) Loi sur l'Énergie (LEne) du 30 septembre 2016. Bern

Consequential-lca (2015a) Further theory on the special case of electricity - forecasting and time horizon www.consequential-lca.org. Accessed 9 Sep 2016

Consequential-lca (2015b) When all co-products have Alternatives. www.consequential-lca.org. Accessed 6 Nov 2017

Cox B, Mutel C, Bauer C et al (2018) Uncertain environmental footprint of current and future battery electric vehicles. Environ Sci Technol 52:4989-4995

Cucurachi S, Suh S (2017) Cause-effect analysis for sustainable development policy. Environ Rev 379:er-2016-0109

Dandres T, Vandromme N, Obrekht G, Wong A, Nguyen KK, Lemieux Y, Cheriet M, Samson R (2017) Consequences of future data center deployment in Canada on electricity generation and environmental impacts: a 2015-2030 prospective study. J Ind Ecol 21:1312-1322

De Rosa M, Knudsen MT, Hermansen JE (2016) A comparison of Land Use Change models: Challenges and future developments. J Clean Prod 113:183-193. https://doi.org/10.1016/j.jclepro.2015.11.097

Ekvall T, Weidema BP (2004) System boundaries and input data in consequential life cycle inventory analysis. Int J Life Cycle Assess 9: $161-171$

European Commission (2016) EU Reference Scenario 2016

Finance BNE (2016) New energy outlook 2016, London

Finnveden G, Hauschild MZ, Ekvall T, Guinée J, Heijungs R, Hellweg S, Koehler A, Pennington D, Suh S (2009) Recent developments in Life Cycle Assessment. J Environ Manag 91:1-21

Frischknecht R (2016) 62nd LCA Discussion Forum - LCA and decision making: when and how to use consequential LCA? In: How to derive a consequential national electricity mix: the Swiss case. ETH Zurich, Zurich

Frischknecht R, Benetto E, Dandres T, Heijungs R, Roux C, Schrijvers D, Wernet G, Yang Y, Messmer A, Tschuemperlin L (2017) LCA and decision making: when and how to use consequential LCA; 62nd LCA forum, Swiss Federal Institute of technology, Zürich, 9 September 2016. Int J Life Cycle Assess 22:296-301

Ghose A, Pizzol M, McLaren SJ (2017) Consequential LCA modelling of building refurbishment in New Zealand- an evaluation of resource and waste management scenarios. J Clean Prod 165:119-133

Gibon T, Arvesen A, Hertwich EG (2017) Life cycle assessment demonstrates environmental co-benefits and trade-offs of low-carbon electricity supply options. Renew Sust Energ Rev 76:1283-1290

Goedkoop M, Huijbregts M, Heijungs R et al (2008) A life cycle impact assessment method which comprises harmonised category indicators at the midpoint and the endpoint level

Graham P (2015) Future grid forum - 2015 refresh technical report. Newcastle

Hauschild MZ, Goedkoop M, Guinée J, Heijungs R, Huijbregts M, Jolliet O, Margni M, de Schryver A, Humbert S, Laurent A, Sala S, Pant R (2013) Identifying best existing practice for characterization modeling in life cycle impact assessment. Int J Life Cycle Assess 18:683697

Howell WL, Schwab K (2018) World Economic Forum Annual Meeting 2018 Creating a Shared Future in a Fractured World

Igos E, Rugani B, Rege S, Benetto E, Drouet L, Zachary DS (2015) Combination of equilibrium models and hybrid life cycle-inputoutput analysis to predict the environmental impacts of energy policy scenarios. Appl Energy 145:234-245

International Energy Agency (2016) World energy outlook 2016. Paris International Energy Agency (2017a) World Energy Outlook Paris International Energy Agency (2017b) IEA World Energy Statistics and Balances. Paris
International Energy Agency (IEA) (2016) World energy model. Paris Itten R, Frischknecht R, Stucki M et al (2012) Life Cycle Inventories of Electricity Mixes and Grid Version 1.3. Uster

Kluyver T, Ragan-kelley B, Pérez F et al (2016) Jupyter notebooks-a publishing format for reproducible computational workflows. Position Power Acad Publ Play Agents Agendas, pp 87-90. doi: https://doi.org/10.3233/978-1-61499-649-1-87

Krakowski V, Assoumou E, Mazauric V, Maïzi N (2016) Feasible path toward $40-100 \%$ renewable energy shares for power supply in France by 2050: a prospective analysis. Appl Energy 171:501-522

Laurent A, Espinosa N, Hauschild MZ (2018) LCA of energy systems. In: Hauschild MZ, Rosenbaum RK, Olsen SI (eds) Life cycle assessment theory and practice. Springer Nature, Cham

Le réseau de transport de l'électricité (2017) Bilan prévisionnel de l'équilibre offre- demande d'électricité en France. La Défense

Majeau-Bettez G, Dandres T, Pauliuk S, Wood R, Hertwich E, Samson R, Strømman AH (2018) Choice of allocations and constructs for attributional or consequential life cycle assessment and input-output analysis. J Ind Ecol 22:656-670

Margni M (2016) Évaluation des impacts du cycle de vie (partie I). Polytechnique Montreal

Marvuglia A, Benetto E, Rege S, Jury C (2013) Modelling approaches for consequential life-cycle assessment (C-LCA) of bioenergy: critical review and proposed framework for biogas production. Renew Sust Energ Rev 25:768-781

Mathiesen BV, Munster M, Fruergaard T (2009) Uncertainties related to the identification of the marginal energy technology in consequential life cycle assessments. J Clean Prod 17:1331-1338

Mendoza Beltran A, Cox B, Mutel C et al (2018) When the background matters using scenarios from integrated assessment models (IAMs) in Prospective LCA

Menten F, Tchung-Ming S, Lorne D, Bouvart F (2015) Lessons from the use of a long-term energy model for consequential life cycle assessment: the BTL case. Renew Sust Energ Rev 43:942-960

Ministerio de Energía Gobierno de Chile (2017) Proceso de Planificación Energética de Largo Plazo. In: Santiago

Muñoz I (2015) Example - marginal electricity in Denmark. In: consequential-lca.org. http://consequential-lca.org/clca/marginalsuppliers/the-special-case-of-electricity/example-marginalelectricity-in-denmark/. Accessed 15 Nov 2016

Muñoz I, Schmidt J, De Saxcé M et al (2015) Inventory of country specific electricity in LCA - consequential scenarios version3.0. Aalborg

Muñoz I, Rodriguez C, Gillet D, Moerschbacher BM (2017) Life cycle assessment of chitosan production in India and Europe. Int J Life Cycle Assess 23:1151-1160

Mutel C (2017) Brightway: an open source framework for life cycle assessment. J Open Source Softw 2:11-12

Mutel C (2018) Slicing, dicing, \& general fun. https://chris.mutel.org/ slicing-dicing-fun.html. Accessed 27 Apr 2018

National Energy Board of Canada (2016) Canada's Energy Future 2016 Update - Energy supply and demand projection to 2040

Nordic Energy Research, International Energy Agency (2016) Nordic energy technology perspectives 2016. Paris

Pauliuk S, Hertwich EG (2016) Prospective models of society's future metabolism: what industrial ecology has to contribute. In: Clift R, Druckman A (eds) Taking stock of industrial ecology. Springer International Publishing, Cham, pp 21-43

Pfenninger S, Hawkes A, Keirstead J (2014) Energy systems modeling for twenty-first century energy challenges. Renew Sust Energ Rev 33:74-86

Pizzol M, Scotti M (2017) Identifying marginal supplying countries of wood products via trade network analysis. Int J Life Cycle Assess 22:1146-1158. https://doi.org/10.1007/s11367-016-1222-6

Prognos (2012) Energieszenarien für die Schweiz bis 2050, Zwischenbericht 1. Basel 
Prox M, Curran MA (2017) Consequential life cycle assessment. In: Curran MA (ed) Goal and scope definition in life cycle assessment, LCA Compen. Springer, Rock Hill, SC, USA

Rajagopal D (2017) A step towards a general framework for consequential life cycle assessment. J Ind Ecol 21:261-271

Reinhard J, Mutel CL, Wernet G, Zah R, Hilty LM (2016) Contributionbased prioritization of LCI database improvements: method design, demonstration, and evaluation. Environ Model Softw 86:204-218

Rosenberg E, Espegren KA, Holden E et al (2015) CenSES energy demand projections towards 2050 - reference path. Trondheim

Roux C, Schalbart P, Peuportier B (2017) Development of an electricity system model allowing dynamic and marginal approaches in LCA tested in the French context of space heating in buildings. Int J Life Cycle Assess 22:1177-1190

Sacchi R (2018) A trade-based method for modelling supply markets in consequential LCA exemplified with Portland cement and bananas. Int J Life Cycle Assess 23:1966-1980

Salou T, Le-Mouël C, Levert F et al (2018) Combining life cycle assessment and economic modelling to assess environmental impacts of agricultural policies: the case of the French ruminant sector. Int J Life Cycle Assess. https://doi.org/10.1007/s11367-018-1463-7

Schmidt JH, Thrane M, Merciai S, Dalgaard R (2011) Inventory of country specific electricity in LCA - consequential and attributional scenarios. Aalborg

Scholten K, Fynes B (2017) Risk and uncertainty management for sustainable supply chains. In: Bouchery Y, Corbett CJ, Fransoo JC, Tan $\mathrm{T}$ (eds) Sustainable supply chains: a research-based textbook on operations and strategy. Springer International Publishing, Cham, pp 413-436

Steubing B, Wernet G, Reinhard J, Bauer C, Moreno-Ruiz E (2016) The ecoinvent database version 3 (part II): analyzing LCA results and comparison to version 2. Int J Life Cycle Assess 21:1269-1281

Stocker TF, Qin D, Plattner G et al (2013) Climate change 2013. Cambridge University Press, Cambridge, United Kingdom and New York, NY, USA

Treyer K, Bauer C (2016) Life cycle inventories of electricity generation and power supply in version 3 of the ecoinvent database part II: electricity markets. Int J Life Cycle Assess 21:1255-1268

U.S. Energy Information Administration (2017) Annual energy outlook 2017 with projections to 2050 . Washington

Vadenbo C, Hellweg S, Astrup TF (2017) Let's be clear(er) about substitution: a reporting framework to account for product displacement in life cycle assessment. J Ind Ecol 21:1078-1089
Vandepaer L, Gibon T (2018) The integration of energy scenarios into LCA: LCM2017 conference workshop, Luxembourg, September 5, 2017. Int J Life Cycle Assess 23:970-977

Vandepaer L, Cloutier J, Bauer C, Amor B (2018) Integrating batteries in the future Swiss electricity supply system: a consequential environmental assessment. J Ind Ecol. https://doi.org/10.1111/jiec.12774

Weidema BP (2004) Geographical, technological, and temporal delimitation in LCA. UMIP 2003 method. København: Miljøstyrelsen. (Environmental News 74). http://lca-net.com/p/1046

Weidema BP (2017) Estimation of the size of error introduced into consequential models by using attributional background datasets. Int J Life Cycle Assess 22:1241-1246

Weidema BP, Ekvall T, Heijungs R (2009) Guidelines for application of deepened and broadened LCA. CALCAS D18, pp 49

Weidema BP, Bauer C, Hischier R et al (2013) The ecoinvent database: overview and methodology, Data quality guideline for the ecoinvent database version 3

Wernet G, Bauer C, Steubing B, Reinhard J, Moreno-Ruiz E, Weidema B (2016) The ecoinvent database version 3 (part I): overview and methodology. Int J Life Cycle Assess 21:1218-1130

Whitefoot KS, Skerlos SJ (2016) Market effects in lifecycle assessment: a framework to aid product design and policy analysis. Procedia CIRP 48:336-341

Wiedmann T, Lenzen M (2018) Environmental and social footprints of international trade. Nat Geosci 11:448-461

Wikipedia (2016) Perfect competition. Wikipedia

Wind Europe (2015) Wind energy scenarios for 2030. Brussels

World Energy Council, Accenture Strategy, Paul Scherrer Institut (2016) World energy scenarios 2016. London

Yang Y (2016) Two sides of the same coin: consequential life cycle assessment based on the attributional framework. J Clean Prod $127: 274-281$

Yang Y, Heijungs R (2018a) On the use of different models for consequential life cycle assessment. Int J Life Cycle Assess 23:751-758

Yang Y, Heijungs R (2018b) Moving from completing system boundaries to more realistic modeling of the economy in life cycle assessment. Int J Life Cycle Assess. https://doi.org/10.1007/s11367-018-1532-y

Zamagni A (2013) Identification of the affected processes: challenges and open questions. In: Blanc I (ed) EcoSD annual workshopconsequential LCA. Mines ParisTech 